OPEN ACCESS

Edited by:

Paul Szyszka,

University of Otago, New Zealand

Reviewed by:

Susanne Neupert,

University of Kassel, Germany

Eirik Søvik,

Volda University College, Norway

*Correspondence:

Divya Ramesh

divya.ramesh@uni-konstanz.de

Specialty section

This article was submitted to

Insect Neurobiology,

a section of the journal

Frontiers in Insect Science

Received: 06 February 2021

Accepted: 10 May 2021

Published: 04 June 2021

Citation:

Chatterjee A, Bais D, Brockmann A and Ramesh D (2021) Search

Behavior of Individual Foragers Involves Neurotransmitter Systems

Characteristic for Social Scouting.

Front. Insect Sci. 1:664978.

doi: 10.3389/finsc.2021.664978

\section{Search Behavior of Individual Foragers Involves Neurotransmitter Systems Characteristic for Social Scouting}

\author{
Arumoy Chatterjee ${ }^{1,2}$, Deepika Bais ${ }^{1}$, Axel Brockmann ${ }^{1}$ and Divya Ramesh ${ }^{1,3 *}$ \\ ${ }^{1}$ National Centre for Biological Sciences, Tata Institute of Fundamental Research, Bangalore, India, ${ }^{2}$ School of Chemical and \\ Biotechnology, SASTRA University, Thanjavur, India, ${ }^{3}$ Department of Biology, University of Konstanz, Konstanz, Germany
}

In honey bees search behavior occurs as social and solitary behavior. In the context of foraging, searching for food sources is performed by behavioral specialized foragers, the scouts. When the scouts have found a new food source, they recruit other foragers (recruits). These recruits never search for a new food source on their own. However, when the food source is experimentally removed, they start searching for that food source. Our study provides a detailed description of this solitary search behavior and the variation of this behavior among individual foragers. Furthermore, mass spectrometric measurement showed that the initiation and performance of this solitary search behavior is associated with changes in glutamate, GABA, histamine, aspartate, and the catecholaminergic system in the optic lobes and central brain area. These findings strikingly correspond with the results of an earlier study that showed that scouts and recruits differ in the expression of glutamate and GABA receptors. Together, the results of both studies provide first clear support for the hypothesis that behavioral specialization in honey bees is based on adjusting modulatory systems involved in solitary behavior to increase the probability or frequency of that behavior.

Keywords: honey bee, glutamate, mass spectrometry-LC-MS/MS, GABA, histamine, octopamine

\section{INTRODUCTION}

In honey bees, searching for food sources and collecting the food are performed by two different worker groups, scouts, and recruits (1-3). Depending on the season and colony state, 5 to $25 \%$ of the foragers are scouts and all the others are recruits. Scouts search for new food sources every day; and recruits continue to visit a known food source for as long as the food source provides sufficient good quality food $(2,4)$. Based on these behavioral differences, it was proposed that scouts are similar to novelty seekers in birds and humans $(5,6)$.

In contrast, recruits only search for a food source at the beginning of their foraging career or when they decide to switch a food source, which does not occur very often during their short life $(2,4,7)$. After following a dance, the recruits search for the location of the food using path integration information indicated by the dance that they had followed $(7,8)$. Reaching the vicinity of the area indicated by the dances, they start searching for the food sources likely using odor cues perceived on the dancer $(7,9)$ as well as visual and floral scent cues of flowers in the area $(10,11)$. Apart from that, recruits, that is, foragers continuously foraging at a food source, 
have been shown to initiate a search behavior when the training feeder was experimentally removed (12-16). The search behavior consists of increasing loops centering around the location where they expected the feeder with increasing radius and an orientation in the hive-feeder axis before they return to the hive (12). Furthermore, similar experiments with an unscented feeder in a flight tunnel suggest that honey bee foragers predominantly use path integration and landmark memory when searching for a missing feeder (14).

In this study we explored two phenomena. Reynolds et al. (12) only observed the trajectory of flights when the bees experienced the missing feeder for the first time. Thus, the question remained whether the bees continue to make additional search flights, and if so, whether foragers show differences in their search behavior. We measured flight and hive durations of individually identified foragers for about $2 \mathrm{~h}$ after removing the feeder. The temporal data were sufficient to describe changes in the behavior over time as well as distinguish individual differences in behavior. In addition, we were interested to know whether this search behavior might be regulated by neuromodulator systems involved in scouting behavior linking individual behavior to social division of labor and behavioral specialization (5). There is growing evidence that behavioral specialists might be temporarily tuned in to a specific brain and behavioral state that occurs in any individual of the species when they perform the corresponding solitary behavior (17-19). Comparing brain gene expression in scouts and recruits and manipulative experiments Liang et al. (5) identified that changes in catecholamine (DopR1), glutamate (Eaat-2, Vglut, Glu$R I)$, and $\gamma$-aminobutyric acid signaling $(G a t-a)$ are associated with scouting behavior. Furthermore, manipulative experiments confirmed that glutamate and octopamine treatment increased, and dopamine antagonist treatment decreased the likelihood of scouting $(5,6)$. Thus, we were specifically interested whether these neurotransmitter systems are also involved in search behaviors performed by regular foragers, that is, recruits, when they do not find a known feeder. We used mass spectrometry measurements (20) to test whether the search behavior of recruits which was induced by the removal of a visited feeder is associated with short-term changes in neuromodulators involved in social scouting. The titer measurements were done for two brain areas of behaviorally characterized individual foragers: the central brain comprising the central complex and the mushroom bodies, which have been demonstrated to be involved in visual navigation including path integration and landmark learning (21-24) and the optic lobes pre-processing the visual information used for navigation and landmark memory (25-27).

\section{RESULTS}

\section{Absence of an Expected Feeder Elicited a Series of Search Flights and Subsequent Cessation of Foraging}

Honey bee foragers (BE 1: $n=16,2015$ and $n=16,2020$ ) that had continuously visited a feeder for a few hours immediately initiated a search when they did not find the feeder at the expected location (Figures 1A-C). Already the mean duration of the foraging trip when they did not find the feeder (FS, combined foraging/search flight; Supplementary Table 1) was significantly longer than the mean duration of the foraging trip (FS, Figures 1D,E). In contrast, the mean duration of the hive stay after this first unsuccessful trip (HFS) was as short as those after the previous regular foraging trips (HF; Figures 1F,G). One of the foragers directly stopped foraging after the FS flight (BeeID: E26; Figure 1C), whereas all the other foragers performed one to four additional search flights (Figures 1B,C). All foragers stopped foraging within $100 \mathrm{~min}$ after the removal of the feeder. The mean duration of the consecutive search flights was relatively consistent (S: $12.37 \pm 6.02 \mathrm{~min}$ ) and lasted about 3 times longer than the mean duration of the foraging trips (F: $3.51 \pm$ $1.02 \mathrm{~min}$; Figures 1D,E; GLMM gamma family and generalized linear hypothesis test; see also Supplementary Table $\mathbf{1}$ for details of the GLMM and GLHT results). In contrast to the search flights, the mean duration of the intermittent hive stays (HS1HS3) increased with the number of search trips (Figures 1F,G; GLMM gamma family and generalized linear hypothesis test; see also Supplementary Table 1 for details of the GLMM and GLHT results).

In an additional control experiment (BE 2) in which we put the feeder back after $1 \mathrm{~h}$, foragers landed on the feeder as soon as it was opened (Supplementary Figure 1). This finding suggests that the search flights were more or less restricted to the close vicinity of the expected feeder location and the foragers were not searching for any other food location.

\section{Individual Foragers Showed Different Search Phenotypes}

Cluster analysis based on the number and temporal dynamics of the search flights and hive stays identified five different search phenotypes independent of the behavioral experiment (IV; Figures 1H-J; see Supplementary Figure 2A for optimum number of clusters). Cluster 1 includes bees that stopped foraging after the first search flight $(S 1 ; n=3,2015 ; n=5,2020)$ and cluster 2 includes the single forager that already stopped foraging after FS (BeeID: E26, 2020). Foragers in Cluster III ( $n=3,2015$ and $n=7,2020$ ) made two search flights and Cluster IV ( $n=7,2015$ and $n=3,2020)$ made three search flights within the observation period. Cluster III and IV formed the largest groups each with 10 bees. Cluster V comprised three foragers (all in 2015) which performed four search trips (see Supplementary Table 1 for details). As the number of search flights is the parameter with the strongest impact, the different clusters present behavioral phenotypes that vary in their motivation to search and their persistence to continue foraging.

\section{Search Behavior led to a Robust Reduction of Glutamate and GABA Titers in the Central Brain}

Neurotransmitter analysis of the brain parts (Supplementary Figure 3) from different foragers (Supplementary Table 2) was done in multiple batches, each containing samples of bees from all behavioral groups 


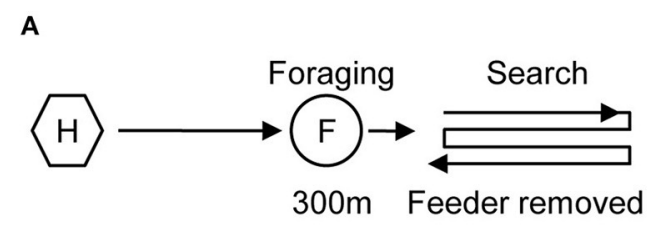

Timeline (min) $\quad \begin{array}{lll}0 \quad 90 & 90\end{array}$
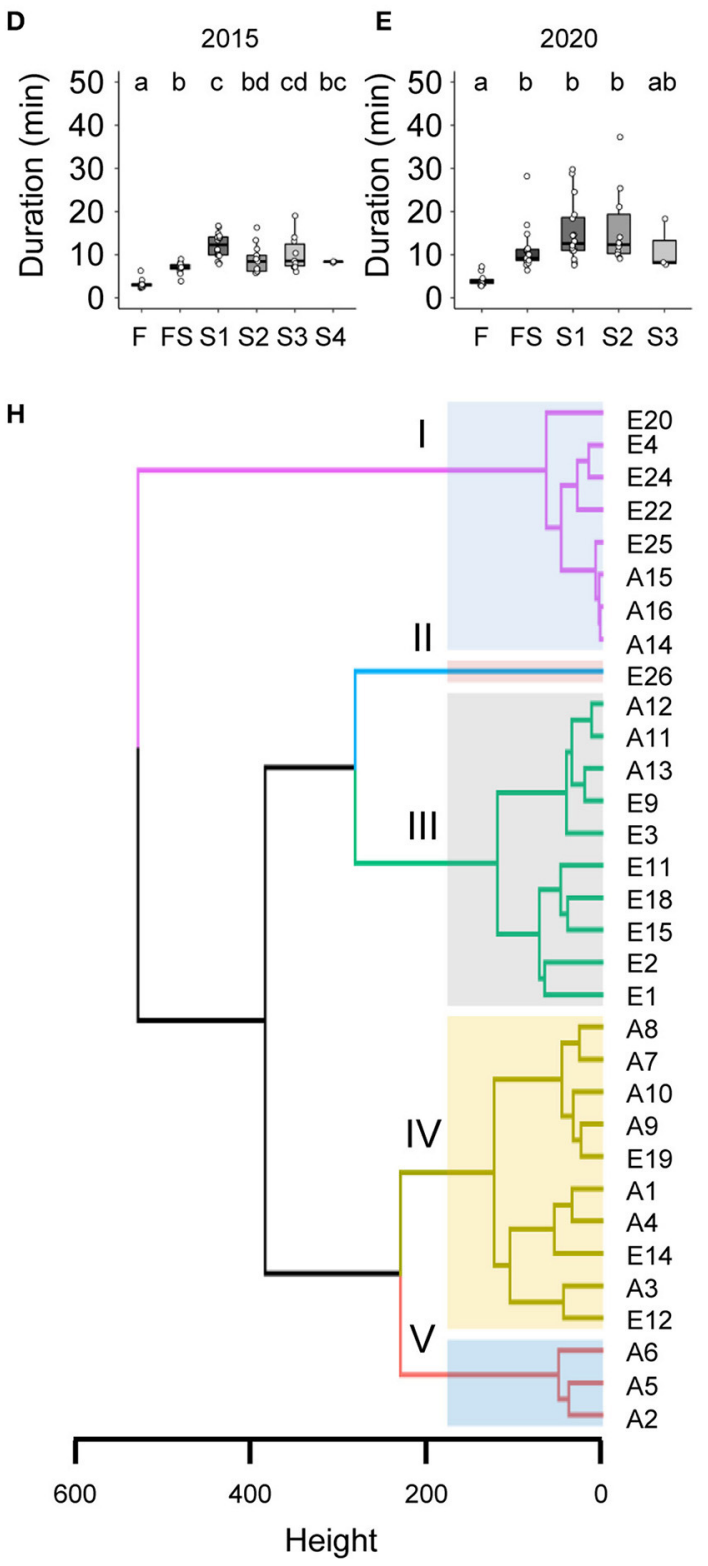
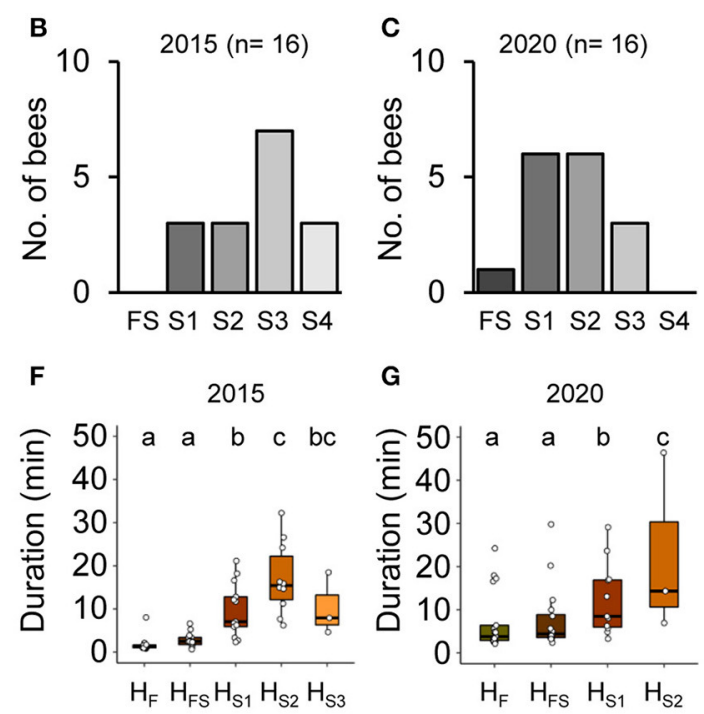

G
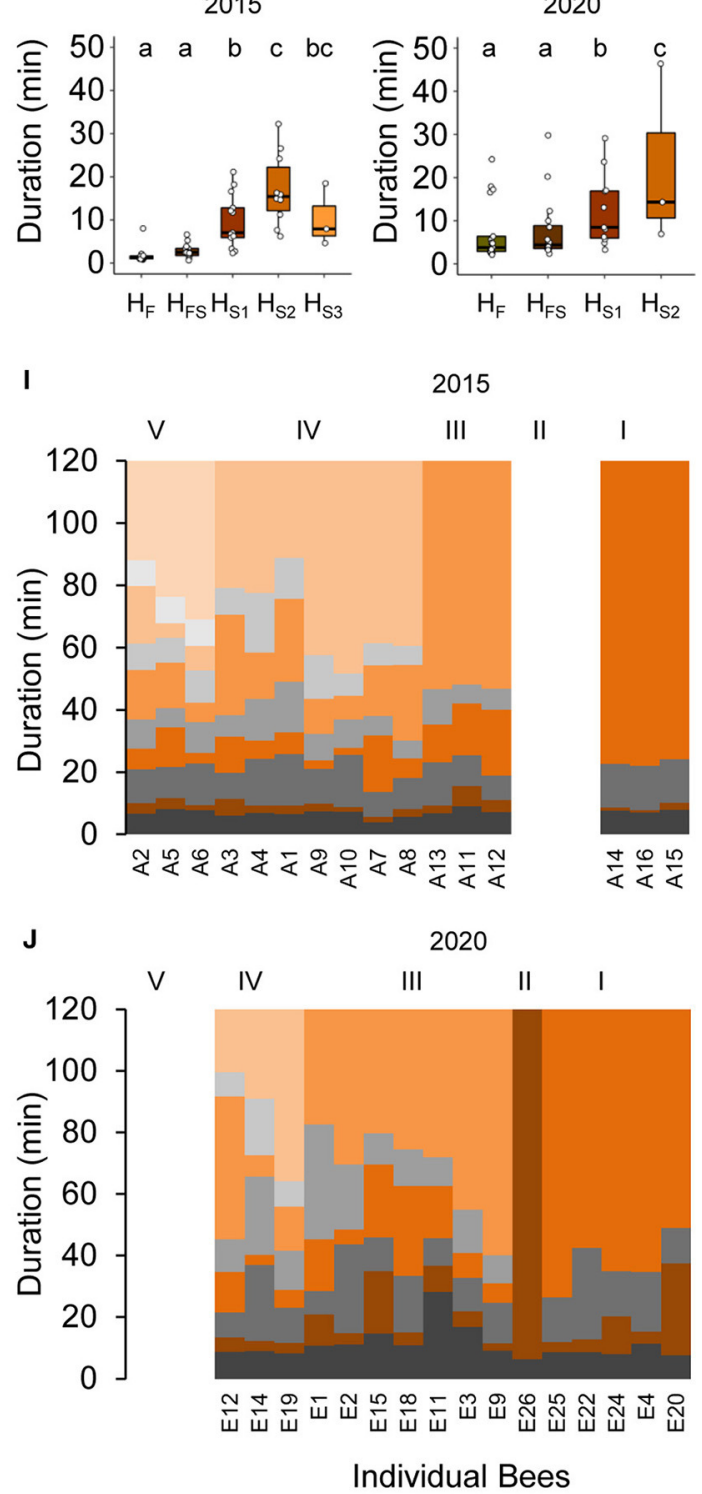

$\begin{array}{llllll}\text { IFS } & \text { IS1 } & \text { IS2 } & \text { S3 } & \text { S4 } & \text { A: } 2015 \\ \text { mHFS } & \text { HS1 } & \text { HS2 } & \text { HS3 } & \text { HS4 } & \text { E: } 2020\end{array}$

FIGURE 1 | Removal of the feeder led foragers to perform search flights. (A) Experimental design to study the dynamics and persistence of search behavior and after foragers were confronted with the absence of a known feeder. Individually marked foragers are allowed to visit the feeder at $300 \mathrm{~m}$ distance from the hive for an initial 1.5 h. The feeder is removed, and the outbound flight activity of the marked foragers is monitored at the hive entrance for the following $2 \mathrm{~h}$. (B, C) Search flights following feeder removal for two colonies. (D,E) Increase in hive-to-hive duration and (F,G) duration of hive stays before and after feeder removal. $\mathbf{( H )}$ Hierarchical clustering of foragers based on search behavior sequence. The maximum average silhouette width 0.58 gave a five-cluster solution with agglomerative coefficient 0.93. (I,J) Search behavior sequences for foragers along with cluster information for two colonies. 
(see Supplementary Material). The batch identity was added as a random factor in the statistical model. Comparing neurotransmitter titers in the central brain (CB) between foragers caught during foraging, searching for the feeder, or revisiting the feeder (Figure 2A), we found robust differences for glutamate and GABA (Figures 2B,C). Foragers that had experienced the absence of the feeder for the first time (FS) and were caught as they were leaving for their first search trip already showed significantly lower GABA titers in the $\mathrm{CB}$ (Figure 2C; decrease by $29.7 \pm 10.3 \mathrm{ng}, p=0.025$ ) than successful foragers. In contrast, glutamate titers in the $\mathrm{CB}$ declined after a first search flight (Figure 2B; decrease by 242.2 $\pm 80.8 \mathrm{ng}, p=0.018$ ). Further, glutamate levels continued to linearly decrease with the number of search trips (Figure 2D; decrease by $111.7 \pm 34.8 \mathrm{ng}$ with every search flight, $p=0.001$ ). Similarly, GABA levels also showed a significant linear decrease, however, the largest reduction occurred during the FS trip and the following hive stay (Figure 2E; decrease after first experience by $29.5 \pm 10.6 \mathrm{ng}, p=0.032$ ).

In addition to the changes in GABA and glutamate titers, we also found differences in the histamine and aspartate levels in the central brain samples (Figures 2F,G). Foragers with two search flights had significantly higher histamine levels than those that were foraging, and the histamine levels showed a significant linear increase with number of search flights $(0.21 \pm 0.096 \mathrm{ng}$ per search flight, $p=0.025)$. In contrast, aspartate levels showed a
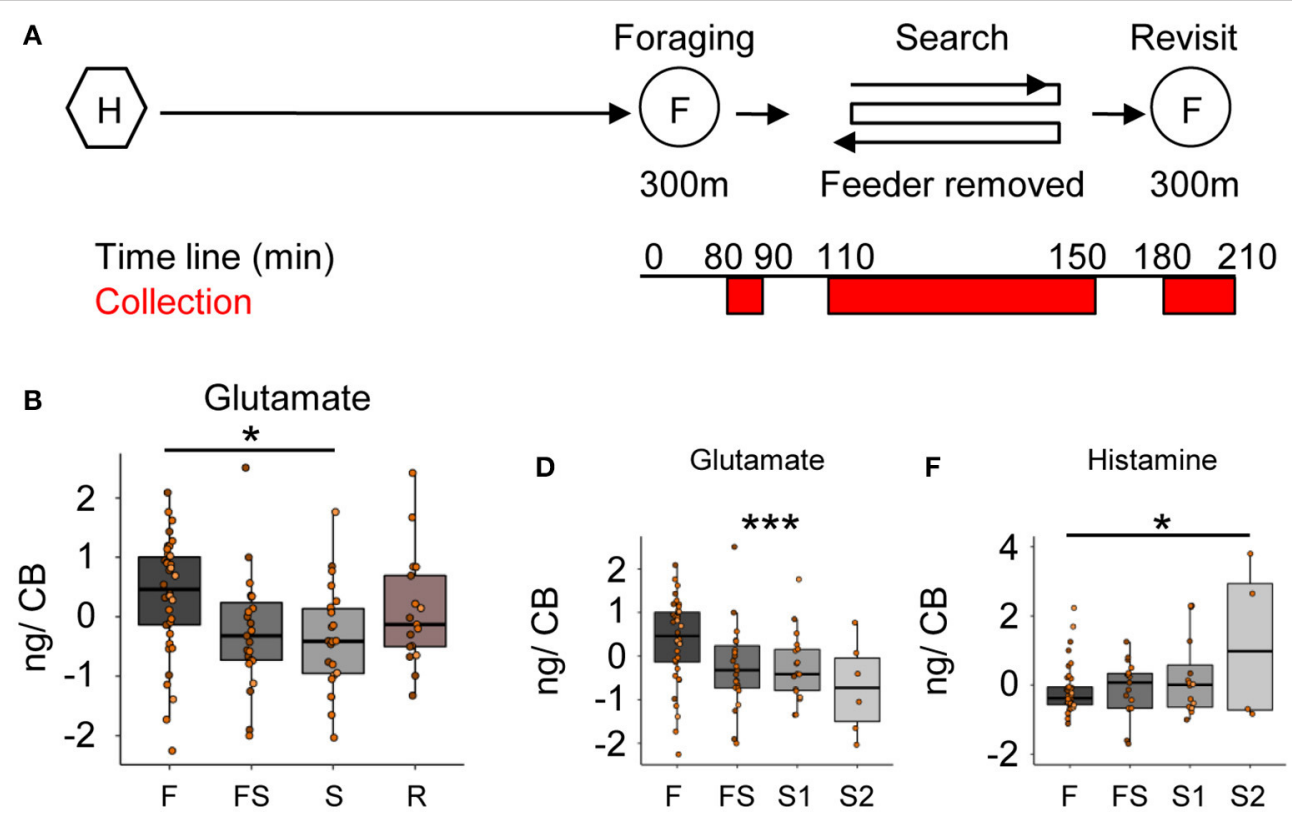

C

E

GABA
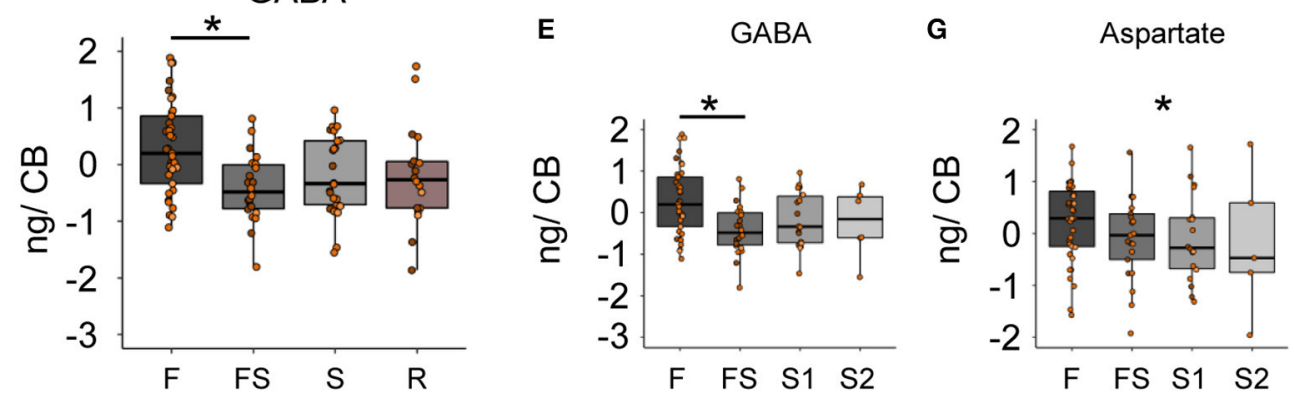

$2017 \bigcirc 2018 \bigcirc 2019$

FIGURE 2 | Search behavior is correlated with reduced GABA and glutamate titers in the central brain. (A) Experimental design to collect foragers for mass spectrometric analysis of brain neurotransmitter titers. Individually marked foragers are allowed to visit the feeder at $300 \mathrm{~m}$ distance from the hive for an initial $1.5 \mathrm{~h}$ (foraging phase). The feeder is removed for $1 \mathrm{~h}$ (search phase) and reinstalled for $1 \mathrm{~h}$ (revisit phase). Foragers were captured at hive entrance during each behavior phase (marked red on experiment timeline). (B,C) Glutamate and GABA levels decrease in the central brain (CB) after bees experience a loss of their expected feeder. (D,E) A detailed look at the dynamics of change indicates that glutamate levels gradually but linearly decrease over increasing search trips (decrease by 112 ng per search flight, $p$-value $=0.001$ ), but GABA levels only decrease post the first experience and stay that way. (F) Histamine (G) Aspartate (decrease by 87 ng per search flight, $p$-value $=0.031$ ). The neurotransmitter values are scaled by the MS batch. ${ }^{*} p<0.05 ;{ }^{* *} p<0.001$. 
significant linear decrease with number of search flights (decrease by $86.8 \pm 40.28 \mathrm{ng}$ per search flight, $p=0.034$ ).

\section{Restarting Foraging led to an Increase of Glutamate and GABA Titers in the Optic Lobes}

In contrast to the $\mathrm{CB}$, we did not detect any changes in neuromodulator titers in the optic lobes (OL) samples during the search flights (Figures 3A-D). However, when we reinstalled the feeder, the foragers, that had restarted foraging, showed significantly higher levels of glutamate and GABA than any other behavioral group (Figures 3A-D). Furthermore, we also found changes in the titers of other neurotransmitters and their precursors in the optic lobes after the bees restarted foraging (Figures $3 \mathrm{E}-\mathrm{O}$ ). Tyrosine and LDOPA, but not dopamine, were significantly higher in foragers that had restarted foraging compared to the foragers visiting before the feeder was removed (Figures 3F,G). Tryptophan, aspartate, histamine, and serine were higher in foragers that restarted foraging compared to those that had performed search flights and those that had foraged before the removal of the feeder (Figures 3K-O; Supplementary Material). All neuromodulators, for which we detected a change, showed a significant increase in their titers due to revisiting the feeder. These dramatic changes were independent of the number of search flights (Supplementary Figure 4).

\section{Forager Search Phenotypes Show Differences in the Titers of HA, Octopamine and L-Dopa}

Based on our findings that foragers differ in their motivation to search and their persistence to forage, we performed a cluster analysis on the individual temporal search dynamics of the collected foragers. Of course, the behavioral data of the collected foragers do not allow a clear identification of the search phenotype for all collected foragers because we collected them during their search behavior instead of after they had stopped leaving the hive. However, we were able to identify a group of foragers that performed several search flights with short intermittent hive stays (Cluster IIIe, Figures $\mathbf{4 A}, \mathbf{B}$ ) and foragers that already showed a long hive stay after the foraging/search flight (FS, Cluster I, Figures 4A,B) before they were collected. With respect to our behavioral analyses, these two search phenotypes strongly differ in their motivation to search. Only for the collection experiment performed in 2018, we found a sufficient number of foragers with different search phenotypes for a comparison of the neurotransmitter levels (Figures 4A,B).

Foragers of the cluster IIIc that had performed two search flights with short intermittent hive stays showed significantly higher DOPA and HA levels and significantly lower octopamine levels in the central brain samples compared to one or more groups of foragers with fewer search flights (Figures 5A-C). Foragers of the cluster IIIc also showed a lower level of aspartate in the optic lobes as compared to foragers of the other three clusters (Figure 5E). This difference was also observed between similar phenotypes in the 2017 collection (Figure 5D).

\section{Colonies Vary Significantly in Their Neurochemical Signatures}

Neurochemical content from the $\mathrm{CB}$ and $\mathrm{OL}$ were quantified from foragers from three different colonies and used for analyzing differences in behavior. In addition to finding changes related to search and restarting of foraging, we found significant differences across colonies as well. A PCA analysis of the CB and OL titers showed that the colonies clustered separately (Figures 6A,B), and that more than $50 \%$ of the variance in transmitter content is explained by the colony differences alone. Individually as well, transmitters showed significant differences between colonies (Figures 6C-O and Supplementary Figure 5). Specifically, the colony used for CE 1 had lower amounts of transmitters in general, in comparison to the other colonies. In the OL, 12 out of 14 transmitters in CE 1 were significantly lower than $\mathrm{CEs} 2$ and 3, while in the $\mathrm{CB}, 10$ transmitters were significantly lower than at least one of the other colonies (Supplementary Figure 5). In spite of the large differences in transmitter titers due to the colony identity, we were still able to detect the changes in neurochemicals due to the behavioral state.

\section{DISCUSSION}

The principal result of our study is that glutamate and GABA titers in the central brain region (comprising mushroom bodies, central complex and adjacent protocerebral areas) decreased during continuous search behavior for a previously visited but absent feeder. This finding corresponds with the fact that the brains of scouts show a higher expression of genes involved in glutamate and GABA signaling. This correlation suggests that the behavioral specialization is based on genomic mechanisms that modulate signaling mechanisms used in regular search behavior.

\section{Search Behavior of Foragers That Do Not Find a Known Feeder at the Expected Location}

Our analyses of the temporal dynamics of flight and hive stay durations of foragers that did not find a known feeder at the expected location suggest that the initiated search behavior consists of a few to several search flights of relatively similar duration (BE 1: range 1-4 search flights; mean $12.37 \pm 6.02 \mathrm{~min}$; range $=5.79-37.3 \mathrm{~min}$, Figures $1 \mathrm{D}, \mathbf{E})$, and intermittent hive stays that get longer with the increasing number of search trips (BE 1: $13.43 \pm 9.37 \mathrm{~min}$, range $=2.33-46.4 \mathrm{~min}$; Figures 1F,G). The duration of the hive stay appears to be a good predictor of the probability to stop the search (and foraging) for a period of time. In the additional control experiment (BE 2), in which we reinstalled the feeder after $1 \mathrm{~h}$, foragers almost immediately started landing on the feeder, indicating that the bees' search flights were more or less restricted to the vicinity of the feeder location.

These observations nicely correspond to findings of other studies in which similar experiments were performed. Radar tracking experiments showed that foragers that did not find the expected feeder started flying in loops around the expected location of the feeder and after some time returned to the hive 


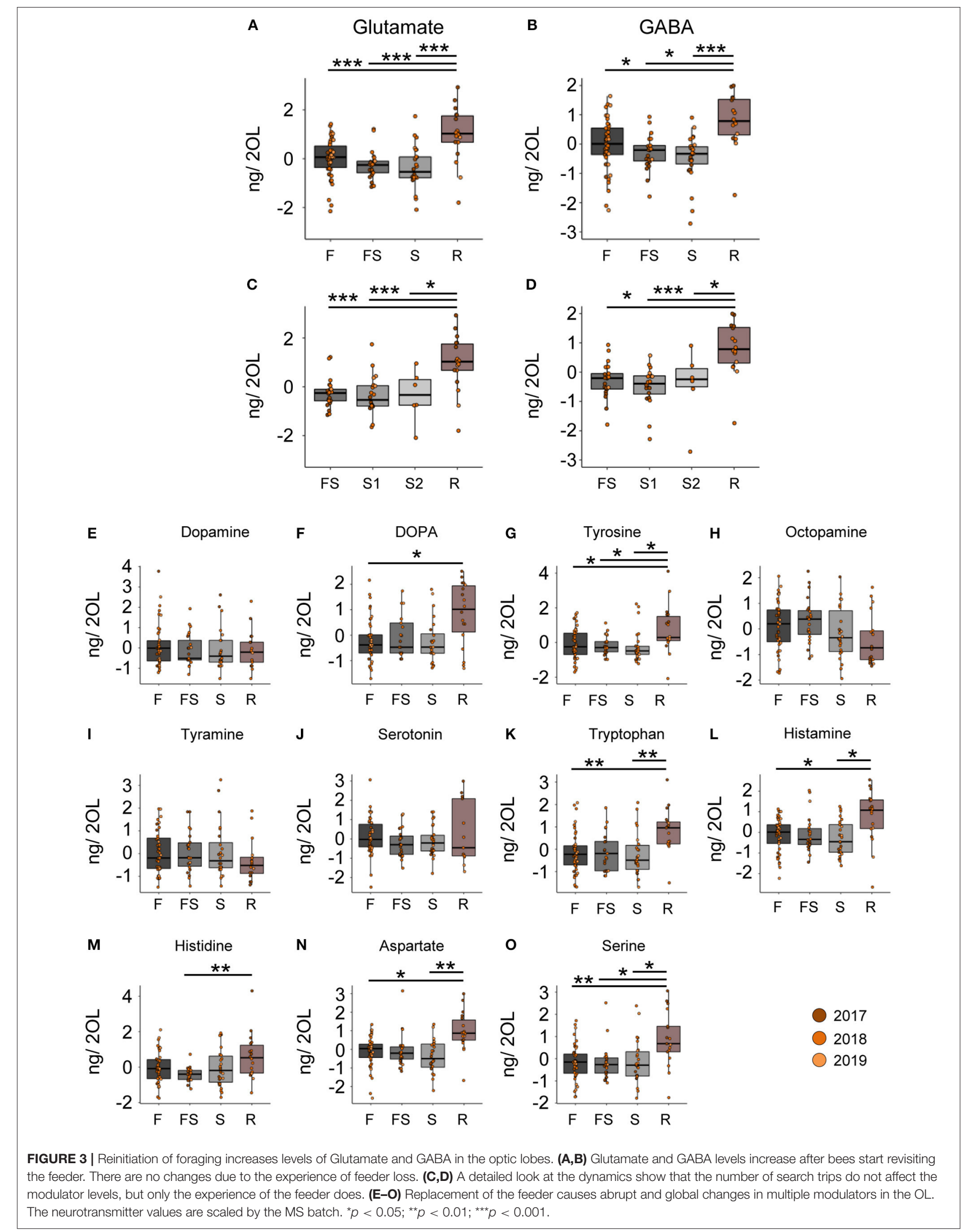


A

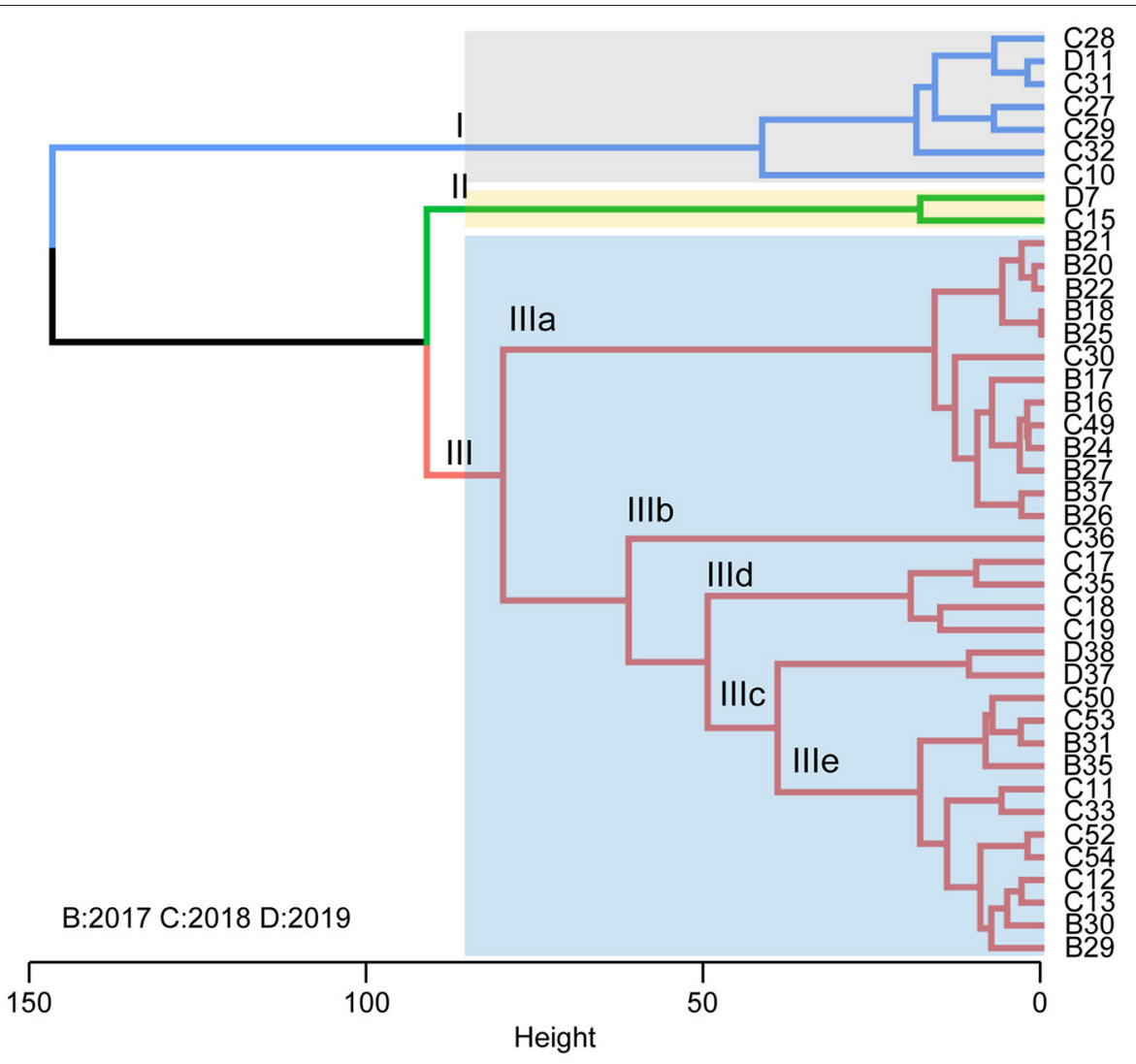

B

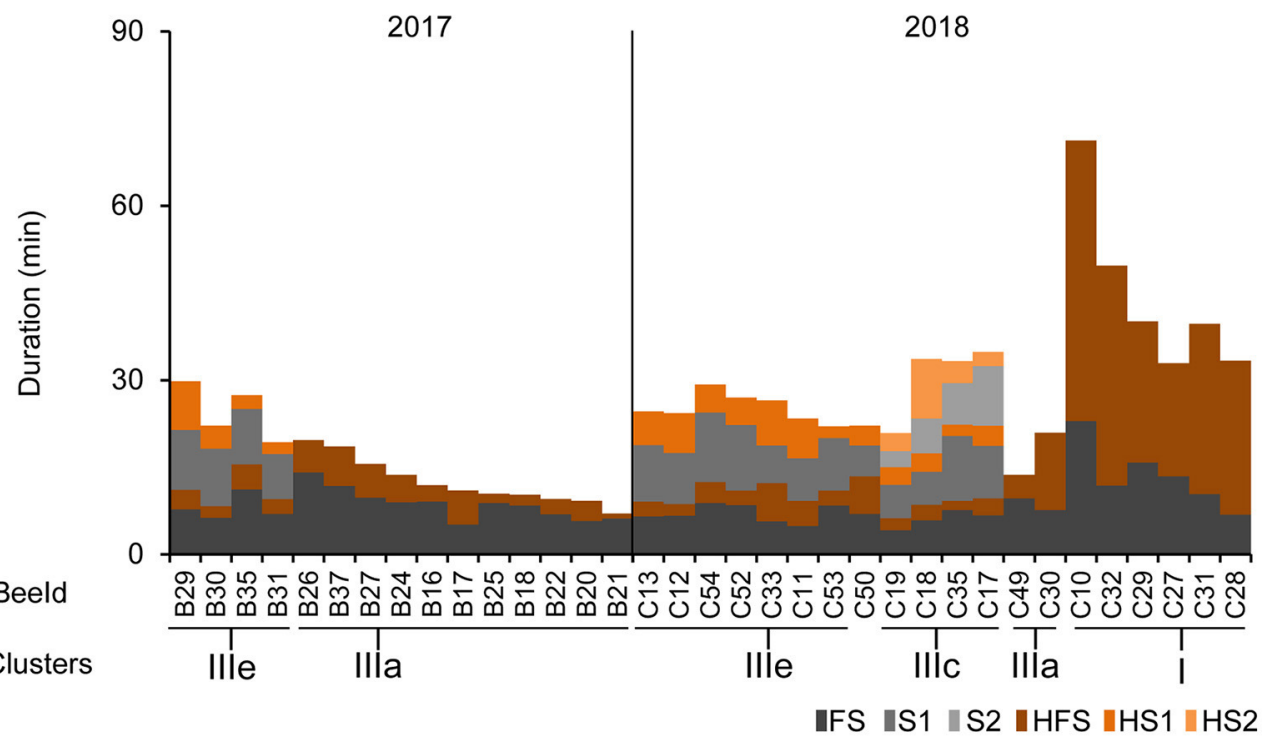

FIGURE 4 | Phenotypes of the collected foragers. (A) Hierarchical clustering of foragers collected during search phase based on search behavior sequences. The maximum average silhouette width 0.52 gave a three-cluster solution with agglomerative coefficient 0.94 . (B) Search behavior sequences for the foragers from the collection experiments along with cluster information. Only bees used for cluster analysis of neurotransmitter titers are shown.

(mean duration $4.49 \pm 2.44 \mathrm{~min}, 12$ ). Furthermore, the search flights were mostly oriented in the hive to feeder direction (12). Al Toufailia et al. (28), reported that foragers trained for a few days revisited an empty feeder at an average of $4.29 \pm 4.47$ trips (range: 0-25) over a 6-h recording period. The persistence to revisit the temporarily unrewarded feeder, measured as number of trips and total duration of trips, correlated with previous foraging experiences, for example, duration of feeder availability 

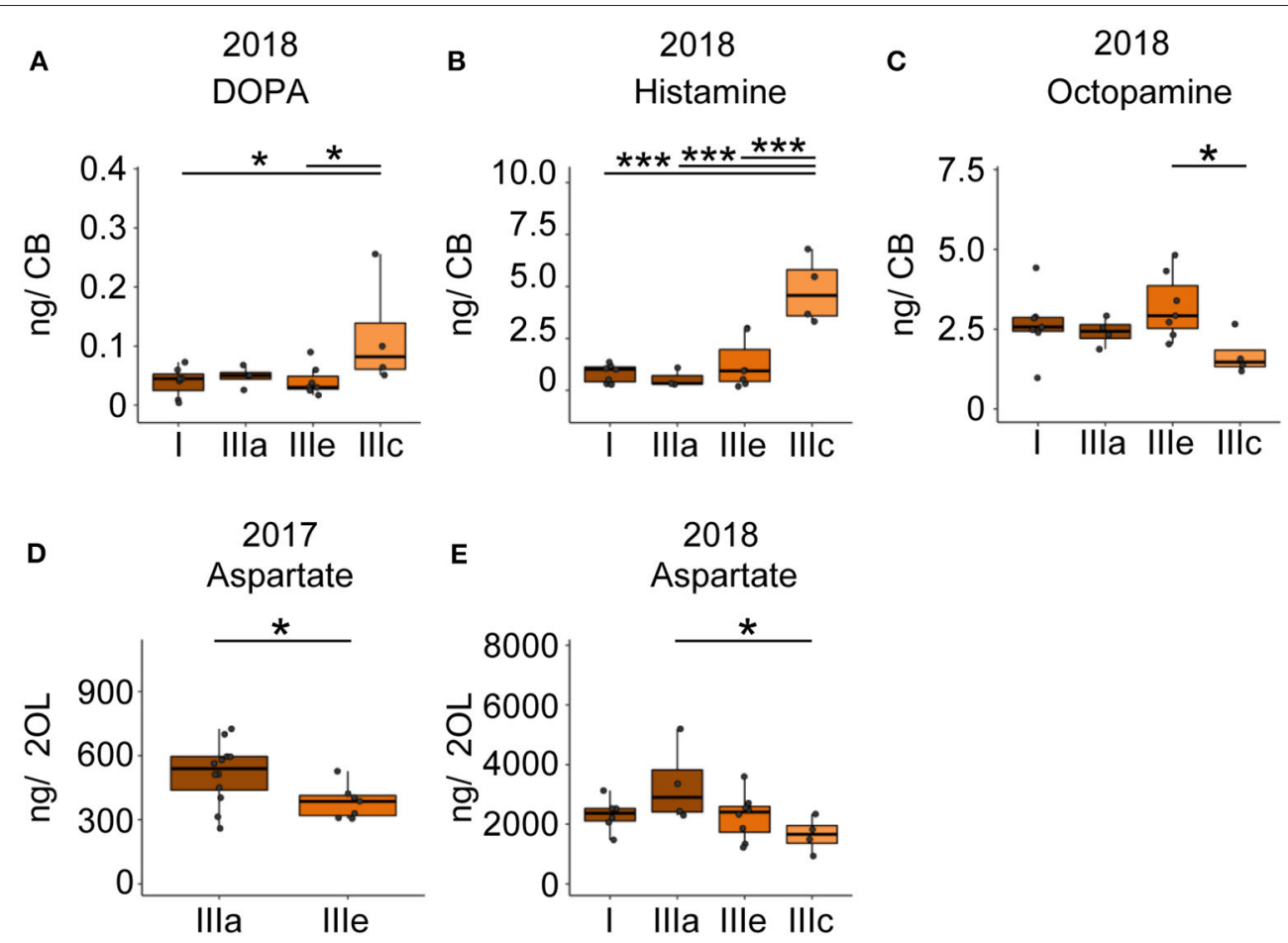

FIGURE 5 | Search intensity negatively correlates with OA and positively correlates with DOPA and HA titers in the CB. (A,B) DOPA and Histamine levels show an increase with increased search trips. (C) Octopamine levels decrease with increased search trips. (D,E) Foragers most motivated to continue search flights showed decreased levels of aspartate in the optic lobes. In addition, bees that performed the FS trip but are phenotypically different in their hive stay times show differences in aspartate levels, though non-significant. Bees without detailed behavior data were added to the phenotype analysis by comparing available relevant behaviors. ${ }^{*} p<$ $0.05 ;{ }^{* \star \star} p<0.001$.

and profitability, as well as season, which affects colony food stores $(15,16,28)$. Furthermore, trained foragers were found to continue to visit an emptied feeder for a few days $[1.89 \pm 1.56$ days, range 0-7 days, (28); see Supplementary Table 3].

Together all these studies indicate that the search behavior elicited by the absence of a known feeder induces a search behavior for this feeder. These foragers are not searching for a new food source or food location as scouts do. Only after repeated unsuccessful visits over a few days, is it reported that the majority of foragers might start searching for a new food source, and that too, most likely only after following dances $(2,29)$. None of the searching bees were found to follow any unmarked dancer during their hive stay within the observation period.

\section{Individual Variation and Search Phenotypes}

In addition to the description of the general temporal dynamics of this search behavior, cluster analysis showed that the individual foragers visiting the same feeder varied in the intensity of search behavior or persistence in revisiting the feeder location. The strongest search response is characterized by fast repetition of search flights which includes short intermittent hive stays. The weakest response was characterized by 1-2 search flights with long intermittent hive stays. These differences are likely based on variations in the behavioral state depending on previous experience and genotype.
In an earlier study, our lab reported that there are consistent long-term individual differences in the dance activity among foragers visiting the same feeder. Interestingly, these differences were, at least to some degree, dependent on the composition of the group (30). Furthermore, the individual variation in dance activity correlated with expression differences in the foraging gene (Amfor). Similarly, linear discriminant analysis of the brain gene expression pattern of individual scouts and recruits showed a separate but overlapping distribution, suggesting a more quantitative than qualitative difference between these phenotypes $(5,29)$. For the future, it will be interesting to explore whether differences in foraging, dance and search activity among foragers visiting the same feeder are correlated and based on the same physiological processes or not. In addition, it would be interesting to see whether scouts resemble one of these forager phenotypes or represent a separate one.

\section{GABA and Glutamatergic Systems Are Involved Both in Search Behavior of Recruits and Scouts}

The comparison of foragers with different numbers of search flights suggest that glutamate and GABA titers continuously decrease with the number of search trips in the central brain (i.e., mushroom bodies, central complex and surrounding protocerebral brain areas). In contrast, glutamate and GABA 
A

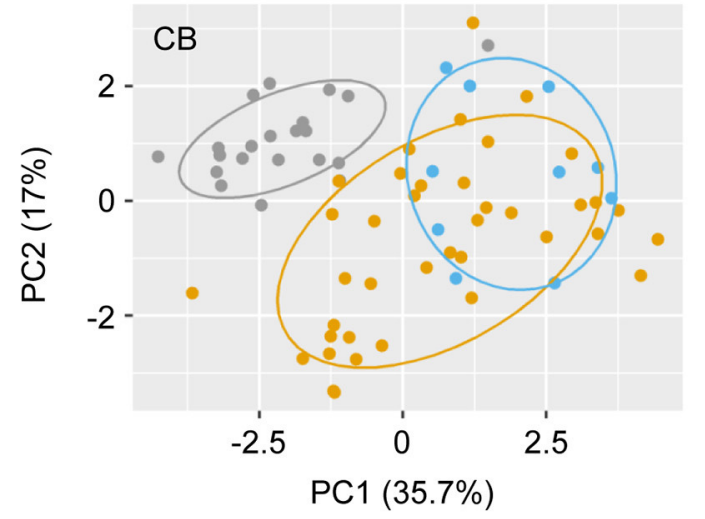

B

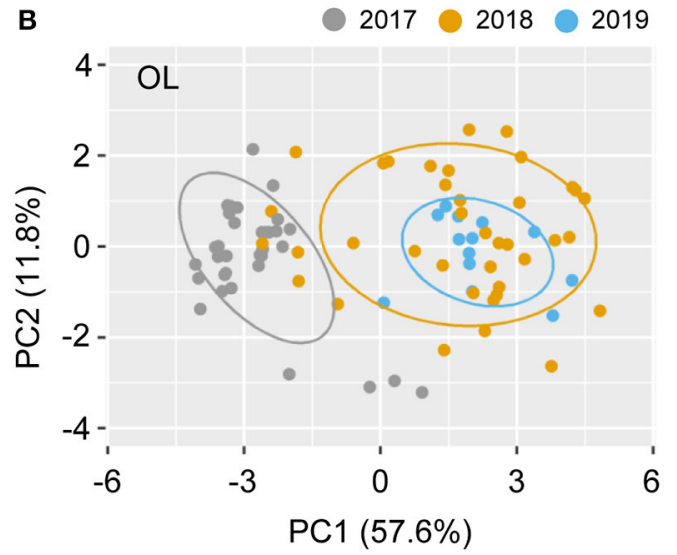

C Glutamate D Dopamine

E Tyrosine $\mathbf{F}$ Octopamine
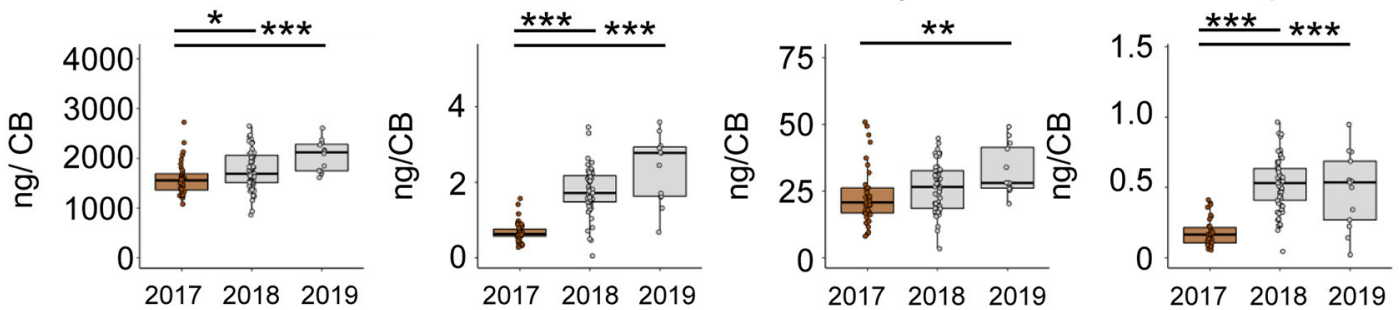

G Tyramine

H Tryptophan

I Histidine $\mathbf{J}$

Aspartate
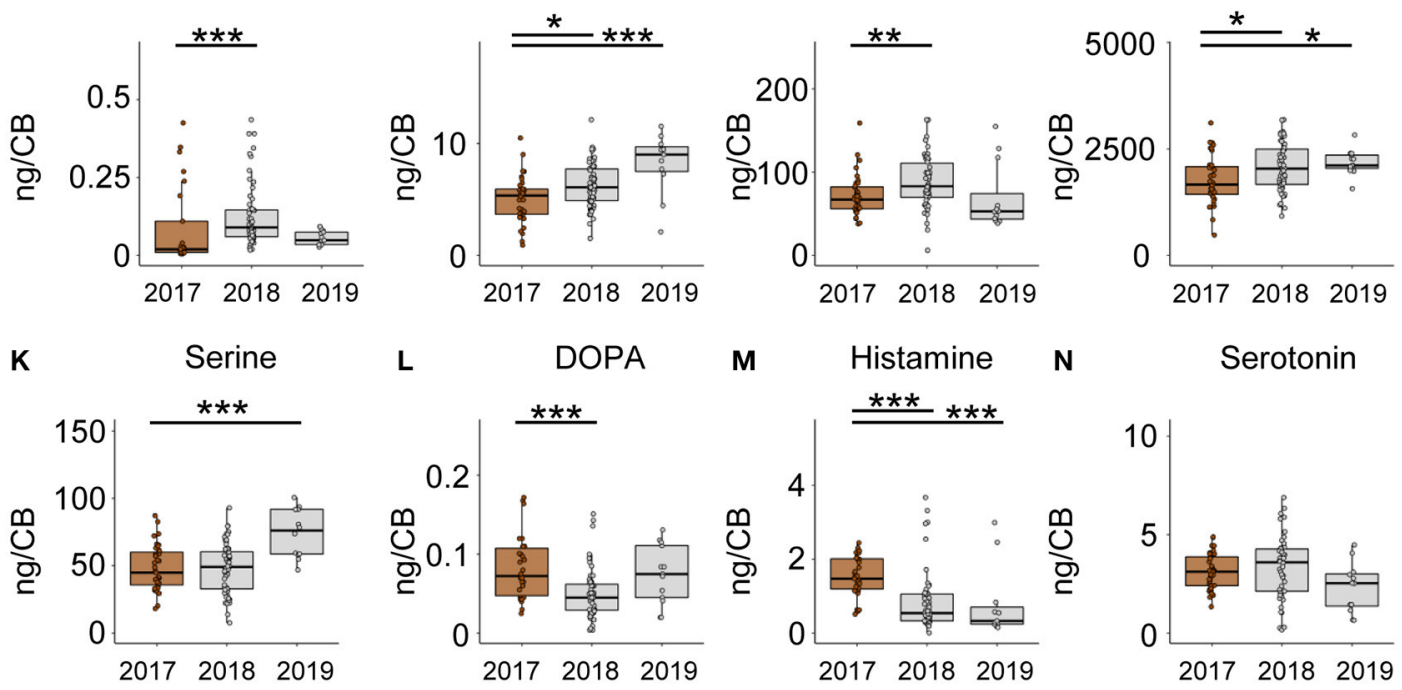

Serotonin

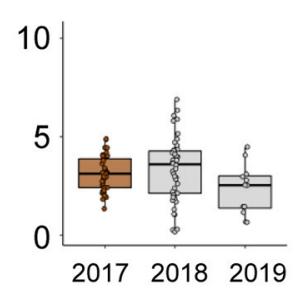

0

GABA

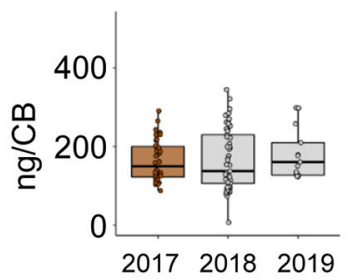

FIGURE 6 | Neuromodulators vary significantly between different colonies. PCA of modulator titers in the CB (A) and OL (B) show $>50 \%$ variance explained by colony membership. (C-O) Individual modulators vary significantly between the different colonies. In general, the 2017 colony shows a lower amount of most transmitters than the 2018 and 2019 colonies. Only the differences between the 2017 and the other 2 years are shown. ${ }^{\star} p<0.05$; ${ }^{* \star} p<0.01$; ${ }^{\star \star \star} p<0.001$. 
titers in the optic lobes did not change during search but showed an abrupt increase when the foragers had started revisiting the feeder. This kind of rebound increase in titers was not observed for the central brain region; moreover, the titers were still lower compared to the foraging group at the beginning of the experiment.

Liang et al. (5) reported a higher expression of several glutamate and GABA receptor and transporter genes in the brains of scouts compared to recruits. In addition, treatment experiments with monosodium glutamate (MSG) increased scouting behavior. Although we do not know the exact function of glutamate and GABA in search behavior (31-34), the comparison of scouts and recruits and our studies on search behavior in foragers (i.e., recruits) strongly suggest that these neuromodulators have an important function in search behavior in general. Changes in the glutamate and GABA signaling appear to be major physiological underpinnings of the behavioral specialization of scout bees. Furthermore, this molecular mechanism might not be unique to honey bees, as it was found that glutamate receptors are also upregulated in scouts of Temnothorax ants (35).

Finally, one of the most original recent molecular studies in honey bees showed an increase in activity in GABA-ergic neurons of the optic lobes during re-orientation flights in which the foragers learn the hive entrance and hive location $(36,37)$. In our behavioral experiments the foragers that found the feeder again also performed learning flights involving circling over the feeder [Supplementary Figure 6; (38)]. Thus, the abrupt increase in GABA titers in the optic lobes in the revisiting foragers might be related to the phenomenon described by Kiya and Kubo (37). GABA-ergic neurons in the optic lobes of Drosophila, for example, are involved in tuning the sensitivity and selectivity of different visual channels $(39,40)$. Similarly, glutamate signaling in the optic lobes is involved in shaping object recognition and directional motion vision (41-43).

In addition to the differences in the glutamate and GABA titers, we found changes in histamine and aspartate. Histamine levels in the $\mathrm{CB}$ increased with the intensity of search (Figures 2F, 5B), and in the OL, they increased due to the re-initiation of foraging (Figure 3L). Aspartate was found to decrease linearly with increasing search trips in the central brain (Figure 2G) as well as in the optic lobes (Figures 5D,E). Later, during the re-initiation of foraging, aspartate levels in the OL increased (Figure 3N). There is growing evidence that neuromodulation in the optic lobes plays a significant role in selecting and adjusting visual processing according to the behavioral context (44). Our results suggest that HA and aspartate, which showed significantly higher titers in the optic lobes of revisiting foragers, might play an important role in modulating visual processing (43, 4547). The changes in the central brain are more difficult to interpret. Previously, we reported that aspartate levels increased globally during anticipation of food (20). It is therefore likely that aspartate and histamine play a role in regulating foraging and motivation [see (48)], although this remains to be investigated.

\section{Forager Search Phenotypes Show Differences in the Titers of HA, Octopamine and L-Dopa}

Comparison of search phenotypes revealed that foragers with a high intensity of search behavior (several successive search flights with short intermittent hive stays, Cluster IIIe) had higher DOPA and HA levels and lower OA levels in the central brain region than foragers with less intense search behavior. These differences in the levels of neurotransmitters among search phenotypes could be a result of a higher degree of neural signaling activity or differences in the baseline levels of neurotransmitter levels among search phenotypes.

Liang et al. (5) reported that octopamine treatment resulted in a weak but significant increase in scouting behavior and that scouts showed a higher expression of the $O c t \beta 2 R$ receptor. Interestingly, they also found that a dopamine antagonist treatment inhibiting dopamine signaling caused a significant decrease in scouting, but their molecular data indicated that dopamine signaling might be downregulated in scouts. The two dopamine receptors, $A m D o p R 1$ and $A m D o p R 2$ showed a lower whole brain expression in scouts compared to non-scouts (5). More recently, Linn et al. (49) showed that foragers treated with octopamine revisited an emptied feeder more often than a sham-treated control group. More importantly, they preferred the known but emptied feeder instead of searching for a new feeder indicated by other nestmates, suggesting that octopamine might increase foraging activity in the sense of persistence (or probability of leaving the hive) but not in a specific sense of searching (50-52). Recently, Cook et al. (32) reported that the brains of scouts showed higher tyramine levels than those of recruits. However, similar to octopamine, the function of tyramine might not be directly involved in search behavior but foraging and flight activity, as suggested by QTL studies on honey bee foraging behavior (53).

\section{Colonies Differ in Neuromodulator Levels as Well as in Search Phenotypes}

In our study, we found that $>50 \%$ of the variance in neurotransmitter titers were due to the identity of the colony from which the foragers were caught (Figures 6A,B). An interesting observation was that the foragers of colony CE 1 showed lower titers compared to foragers of CEs 2 and 3 for almost all neuromodulators tested (Figures 6C-O and Supplementary Figure 4). These were bees that were housed in an observation hive. Many previous studies on honey bees reported variation in brain neurotransmitter and neuromodulator titers with colony state and season $(54,55)$. The colony hosted in the observation hive likely differed from the others in the density and crowding of bees, as well as in the available food stores (impacting the hunger state), both of which are known to affect the neurochemical composition of the brain $(56,57)$. In spite of the large differences in transmitter titers due to the colony identity, we were still able to detect the changes in neurochemicals due to the behavioral state.

Colonies also differed in the composition of search phenotypes. In the behavior experiment (Figures 1I,J) as 
well as in the collection experiment (Figure 4B), performed over 5 years, we found that colonies differed in the presence and relative composition of phenotypes. These differences are likely due to colony conditions and forage availability modulating the foraging force.

\section{Novelty Seeking, Glutamate, GABA and the Honey Bee Brain}

Liang et al. (5) suggested that the brain expression differences between scouts and recruits have something to do with novelty seeking as scouts are obviously searching for new food sites, and studies in vertebrates indicated that the identified neuromodulator systems (glutamate, GABA, and catecholamine) are involved in novelty seeking. Novelty seeking is certainly a complex behavior composed of different behavioral routines or modules, for example, a specific flight pattern and increased visual and olfactory attention when searching for flowers. The differences in the changes in glutamate and GABA titers in the central brain region and optic lobes in our study might correspond to these different behavioral modules. Our finding that GABA titers increase with relearning the re-established feeder corresponds with the finding that GABA neurons in the optic lobes showed an increased activity during relearning the nest entrance and its surrounding after the hive had been experimentally relocated (37). Another question is whether glutamate and GABA initiate or modulate (enhance) search and scouting behavior (58). A recent study in Drosophila, for example, showed that the majority of octopaminergic neurons are also glutamatergic and that both transmitters in these neurons affect the same and different behaviors, and thus might be involved in selection of behavioral modules (59). In honey bees, glutamate and GABA have mainly been studied in the context of learning and memory $(34,60-64)$. A study in ants aimed at identifying negative effects of increased monosodium glutamate consumption over several days showed a decrease in "precision of reaction," a decrease in "the response to pheromones," a decreased "impacted cognitive ability," and "largely reduced learning and memory" (65). Thus, the most plausible assumption at the moment might be that glutamate and GABA are involved in modulating brain circuits involved in search behavior and thus changing probabilities to perform behavioral routines involved in search behavior. The insect central brain region including mushroom bodies, central complex and adjacent protocerebral areas are involved initiating and selecting behaviors (66-69), path integration and landmark learning (21-24); and the optic lobes in pre-processing the visual information used for navigation and landmark memory (25-27).

For the future it would be interesting to identify neuron populations that are involved in search and scouting. One approach would be to perform double in-situ staining for neuronal activity-regulated genes and genes involved in glutamate and GABA signaling in brains of recruits and scouts caught during search behavior, as it was done for re-orienting foragers by $(37,70)$. Having identified neurons involved in searching as well as scouting, one could compare their expression patterns to identify the molecular changes underlying behavioral specialization at the cellular level. Regarding the neuronal mechanisms that determine scouts, it might be promising to first compare how scouts differ from recruits in the search behavior. For example, do scouts perform longer and more extended search flights? Subsequently, one could study whether the gene expression differences between scouts and recruits are based on changes in gene expression in the same cells or an extension of gene expression in different cells and identify in which brain areas these differences occur.

Honey bee foraging at an artificial feeder is one of the most fruitful and successful experimental assays in the study of animal behavior. All the fascinating behavioral and cognitive capabilities of honey bees have been identified using the feeder training assay $(4,7,71)$. As a behavior, foraging can be nicely dissected into different behavioral routines which can be studied separately, for example, anticipating foraging in the hive (20, $72,73)$, flying towards the feeder, food collection at the feeder $(74,75)$, flying back to the hive, and recruiting nestmates with the dance $(13,76)$. In addition, there is increasing evidence that foragers vary in the intensity of each behavioral module $(30,32,77,78)$. We suggest that detailed behavioral experiments combined with sophisticated molecular techniques will help to identify candidate neuronal mechanisms involved in elaborated behavioral and cognitive capabilities $(70,73,79)$. Of course, decisive causal mechanistic studies will only be possible if genetically engineered honey bees are widely available (80-82), or we might use Drosophila for comparative studies to identify neural underpinnings of some of the behavioral modules (83-86).

\section{MATERIALS AND METHODS}

\section{Materials Availability}

Apis mellifera colonies were procured from HoneyDay Bee Farms Pvt. Ltd., Bangalore. All standards, formic acid (FA), hydrochloric acid $(\mathrm{HCl})$, boric acid and ascorbic acid as well as reagents required for 6-aminoquinolyl-N-hydroxysuccinimidyl carbamate (AQC) synthesis were obtained from SigmaAldrich (Bangalore, India). Acetone was obtained from Fisher Scientific. Solid phase extraction cartridges (Strata-X, 8B-S100TAK) were obtained from Phenomenex, Inc. (Hyderabad, India). High purity MS grade solvents (methanol, acetonitrile, and water) were obtained from Merck Millipore (Merck Millipore India Pvt. Ltd., Bangalore). Deuterated internal standards: L-serine-2,3,3-d3, L-glutamic-2,3,3,4,4-d5 acid, L aspartic-2,3,3-d3 acid, L-histidine-d3 ( $\alpha$-d1; imidazole-2,5-d2) $\mathrm{HCl}$ L-tryptophan-2', $4^{\prime}, 5^{\prime}, 6^{\prime}, 7^{\prime}$-d5, L-4-hydroxyphenyl-d4alanine-2,3,3-d3 (tyrosine), 4-aminobutyric-2,2,3,3,4,4-d6 acid (GABA-d6), histamine- $\alpha, \alpha, \beta, \beta-\mathrm{d} 4$, serotonin- $\alpha, \alpha, \beta, \beta-\mathrm{d} 4$, L-dopa-2,5,6-d3, 2-(3,4-dihydroxyphenyl)ethyl-1,1,2,2-d4amine- $\mathrm{HCl}$ (dopamine-d4) and tryptamine- $\alpha, \alpha, \beta, \beta-\mathrm{d} 4$ were obtained from CDN Isotopes (Quebec, Canada). The deuterated internal standards 2-(4-Hydroxyphenyl)ethyl-1,1,2,2-d4-amine $\mathrm{HCl}$ and beta-Hydroxytyramine ( $\alpha-\mathrm{d} 2, \beta-\mathrm{d} 1) \mathrm{HCl}$ were supplied by Medical Isotopes, Inc. (USA). The purity of all analytes and deuterated internal standards was $\geq 98 \%$. Glass beads and the bead beater were purchased from BioSpec. 


\section{Animals and Feeder Training}

Honey bee colonies (Apis mellifera, $\mathrm{N}=6$ ) were located inside the NCBS campus, Bangalore, India. Foragers were trained from the hive to an unscented sugar water feeder (concentration $1.75 \mathrm{M}$ ). The feeder distance was gradually increased to $300 \mathrm{~m}$ from the hive over 2 days and foragers were trained along a road surrounded by dense vegetation in the neighboring UAS-GKVK Campus, Bangalore, India (13).

\section{Behavior Experiments}

Two kinds of behavior experiments were performed. In the first behavior experiment (BE 1$)$, foragers $(n=10-12)$ were colormarked individually prior to the day of the experiment (13). On the day of the experiment, marked foragers were allowed to visit the feeder at $300 \mathrm{~m}$ for $1.5 \mathrm{~h}$ (foraging phase). The feeder was then removed and kept hidden away from the reach of the foragers for another $1.5 \mathrm{~h}$ (search phase; Figure 1A). In the second behavior experiment (BE 2), the feeder was presented initially for $1.5 \mathrm{~h}$ (foraging phase) for marked foragers $(n=50-60)$ to visit. The feeder was then removed for $1 \mathrm{~h}$ (search phase) and reinstalled at $300 \mathrm{~m}$ for another $1.5 \mathrm{~h}$ (revisit phase).

Colonies used for BE $1(N=2,2015$ and 2020) were housed in a glass observation hive located within a wooden hut devoid of any external illumination (13). In case of BE $2(N=1,2019)$ the colony was housed in a Langstroth hive box and placed under the shade of a tree next to the site of the hut. Experiments were performed in the summers between the months of May-July each year.

\section{Collection Experiments}

Three collection experiments (CE 1-3) were performed. During each experiment, color-marked foragers $(n=50-60)$ initially visited the feeder (concentration $2 \mathrm{M}$ ) for $1.5 \mathrm{~h}$ (foraging phase). At the end of the foraging phase (last $10 \mathrm{~min}$ ), color-marked outbound foragers from the hive opening were captured in plastic tubes and flash-frozen in liquid nitrogen. The feeder was then removed and kept hidden during the search phase $(1-1.5 \mathrm{~h})$. Foragers flying out did not find the feeder at $300 \mathrm{~m}$ and came back to the hive. Marked individuals were caught while flying out after 10-90 min of feeder removal. The feeder was reintroduced at $300 \mathrm{~m}$ (revisit phase) and foragers readily continued foraging at the feeder for another hour. Revisiting individuals were captured at the hive entrance making outbound flights, provided each made 3-4 trips to the feeder (Figure 2A).

Colony used for CE $1(N=1,2017)$ was housed in a glass observation hive located within a wooden hut devoid of any external illumination (13). In case of CE 2-3 $(N=2,2018$ and 2019), the colonies were housed in a Langstroth hive box and placed under the shade of a tree next to the site of the hut. Experiments were performed in the summers between the months of May-July each year. For details about numbers of bees analyzed, see Supplementary Table 2.

\section{Monitoring Search Flights}

For BE 1 and CE 1-3, a video camera (Sony HDR-CX220V Tokyo, Japan) was mounted at the hive entrance. Experimenters recorded the number and duration of search flights made by individuals from the time of exit and entry of the foragers in and out of the hive from video playback. Video recordings were done at the feeder for $\mathrm{BE} 2$ during foraging and revisit phase to monitor the rate of bees arriving at the feeder.

\section{Brain Dissections}

The foragers collected in liquid nitrogen were transferred to a $-80^{\circ} \mathrm{C}$ freezer. Individual bee brains were dissected on dry ice into two different parts, the optic lobe pair (OL) and the region of the brain containing the mushroom bodies and the central brain (CB) (Supplementary Figure 3). The brains were dissected out within $6 \mathrm{~min}$ and were never allowed to thaw. The trachea covering the brain becomes a thin film that can easily be brushed off without damaging the brain. We did not rinse the brain in any liquid, in order to preserve the tissue integrity and prevent the degradation of biogenic amines. Brains were dissected and prepared for subsequent mass spectrometric analysis prior to the completion of video analysis and classification of individual bees based on their behavior. Samples were excluded from statistical analysis only if during the video analysis, the bee could not be identified because the marking was blurred, or because of contrast and brightness issues or the bee was upside down, etc.

\section{Selection Criteria for Sample Processing}

From the number of bees that were collected for a given experiment, we made an effort to include equal numbers of samples from all behavioral groups. The selection of samples for MS processing and analysis was done based on the time of capture during the collection experiment (foraging, searching and revisiting) whereas the final classification of the behavioral group was done only after time-consuming video analysis. Statistical analysis was done on F, S and R as well as F, FS, S1, S2 and $\mathrm{R}$ depending on the behavioral phenotype identified in the video analysis. Samples were excluded from statistical analysis if the bee could not be identified during the video analysis because the marking was blurred, or because of contrast and brightness issues or the bee was upside down etc. As a consequence of the delayed behavioral analysis, several of the samples for which we had mass spectrometric data could not be incorporated in the final statistical analysis.

\section{Mass Spectrometry of Neurotransmitters}

For mass spectrometric measurements, brain samples were prepared as in Ramesh and Brockmann (20). Briefly, to the vial containing the individual bee brain part, $100 \mu \mathrm{l}$ of $0.5 \mathrm{~mm}$ glass beads, $190 \mu \mathrm{l}$ of acetone containing $0.1 \%$ formic acid, $10 \mu \mathrm{l}$ of $10 \mathrm{mM}$ freshly prepared ascorbic acid, and $10 \mu \mathrm{l}$ of $0.5 \mu \mathrm{g} / \mathrm{ml}$ internal standard mixture was added. Five microliters of a 0.5 $\mu \mathrm{g} / \mathrm{ml}$ serotonin and tryptamine mixture was added to each sample (spiked) to aid quantification of these low ionizing and high matrix suppressed compounds. A bead beater was used to homogenize the samples, and the supernatant was collected in a new vial and lyophilized. For the derivatization procedure, $80 \mu \mathrm{l}$ of $200 \mathrm{mM}$ borate buffer and $10 \mu \mathrm{l}$ of $10 \mathrm{mM}$ ascorbic acid was added to the lyophilized extract, mixed well and $10 \mu \mathrm{l}$ of a freshly prepared solution of $10 \mathrm{mg} / \mathrm{ml} \mathrm{AQC}$ was added. The reaction 
was incubated at $55^{\circ} \mathrm{C}$ for $10 \mathrm{~min}$ and stopped by the addition of $3 \mu \mathrm{l}$ of $100 \%$ formic acid.

MS grade water $(500 \mu \mathrm{l})$ was then added to the samples, and samples were loaded onto activated and equilibrated RPSPE columns and washed twice with $1 \mathrm{ml}$ of water containing $0.1 \%$ formic acid. Elution was done with $1 \mathrm{ml}$ of ACN-MeOH (4:1) containing $0.1 \%$ formic acid and lyophilized and stored at $-20^{\circ} \mathrm{C}$ until injection into the instrument. Samples were reconstituted in $50 \mu \mathrm{l}$ of $2 \% \mathrm{ACN}$ containing $0.5 \%$ formic acid. The calibration curves range for each compound were made according to the abundance in the biological matrix and were the same as in Ramesh and Brockmann (20) and are given in the Supplementary Material. Comparison of instrument responses for calibration curves over the 3 years of measurements are given in Supplementary Figure 7.

A Thermo Scientific TSQVantage triple stage quadrupole mass spectrometer (Thermo Fisher Scientific, San Jose, CA, USA), connected to an Agilent 1290 infinity series UHPLC system (Agilent Technologies India Pvt. Ltd., India) was used for the neurochemical quantification. The column oven was set at $40^{\circ} \mathrm{C}$, and the autosampler tray at $4^{\circ} \mathrm{C}$. The mobile phase solvent $\mathrm{A}$ was $10 \mathrm{mM}$ ammonium acetate containing $0.1 \%$ formic acid, and solvent B was ACN containing $0.1 \%$ formic acid. A C- 18 column $(2.1 \mathrm{~mm} \times 100 \mathrm{~mm}, 1.8 \mu \mathrm{m}$, Agilent RRHD ZORBAX) fitted with a guard column $(2.1 \mathrm{~mm} \times 5 \mathrm{~mm}, 1.8 \mu \mathrm{m}$ Agilent ZORBAX SBC18) was used. The LC gradient was as follows: $(2 \% \mathrm{~B}$ at $0 \mathrm{~min}$, $2 \% \mathrm{~B}$ at $3 \mathrm{~min}, 20 \% \mathrm{~B}$ at $20 \mathrm{~min}, 35 \% \mathrm{~B}$ at $25 \mathrm{~min}, 80 \% \mathrm{~B}$ at $25-$ $27 \mathrm{~min}, 2 \% \mathrm{~B}$ at $27-35 \mathrm{~min}$ ) at a flow rate of $0.2 \mathrm{ml} / \mathrm{min}$. The MS operating conditions were as follows: $3,700 \mathrm{~V}$ spray voltage (positive ion mode); $270^{\circ} \mathrm{C}$ capillary temperature; 20 (arbitrary units) sheath gas pressure; 10 (arbitrary units) auxiliary gas; argon collision gas. The S lens voltage and collision energy were as given in Ramesh and Brockmann (20), and are also provided in the Supplementary Material. Quantification was done using the Xcalibur software version 2.2. Mass spectrometric measurements of the brain samples were done at the NCBS in-house facility.

\section{Sample Stability and Storage}

Frozen and dissected brains can be stored in the $-80^{\circ} \mathrm{C}$ deep freezer for up to a year and processed and freeze-dried samples can be stored in the -20 freezer for up to 2 weeks. Known amounts of deuterated internal standards are added before any kind of sample processing is done, to normalize for any sample loss throughout. Compounds remain highly stable over multiple weeks under lyophilized conditions, post derivatization. In aqueous solutions, the AQC derivatized products start degrading, but the samples were reconstituted only just before injection. Under aqueous conditions, $80 \%$ of the ion intensity is still present after $48 \mathrm{~h}$. Validation of this method has also been done previously by others (87).

\section{Statistical Analysis Classification of Outbound Trips}

Trips of the foragers were classified based on the foragers' knowledge whether the feeder was present or not into F, FS and $S$ (Supplementary Table 1). In both F and FS, a forager flying out of the hive had the information that the feeder was present whereas in S(s) the forager had the information that the feeder is no more present.

\section{Changes in Hive-To-Hive Duration and Hive Stays}

For behavior experiment BE 1, we wanted to know if the removal of the feeder led to changes in (a) hive-to-hive duration for an outbound flight and (b) duration of the hive stays between two outbound trips. We used a generalized linear mixed-effects model (GLMM) with a Gamma error distribution, considering the individual identity of the bee as a random factor (individual effect). We compared (a) hive-to-hive duration (F, FS and S14) and (b) duration of hive stay following outbound flights (HF, HFS, HS1-3) using a generalized linear hypothesis test (GLHT). $P$-values were corrected for multiple testing using single step adjustment. Distribution structures of the data were determined prior to model building by comparing AIC values as a goodness of fit criteria. Models were used separately for the two colonies.

Determination of distribution structures, GLMM and GLHT were done using the "fitdistrplus," "lme4" and "multcomp" packages, respectively, in $\mathrm{R}$ version 4.0.2.

\section{Search Behavior Sequence and Cluster Analysis}

A combination of sequence and cluster analysis (88) was used to identify common search behavior patterns among individual foragers following feeder removal in the behavior experiment BE 1. First, consecutive search flights and in-between hive stays for a forager were arranged as a search behavior profile. Each profile started with the exit of the bee for FS $(t=0 \mathrm{~min})$ and was terminated at $120 \mathrm{~min}$. When a bee came back from a search flight and did not appear outside until the end of the observation period, the time the forager spent inside the hive was counted as her final hive stay. For example, if a bee made four search flights, the search behavior profile would include the search behavior states: "FS - HFS - S1 - HS1 - S2 - HS2 - S3 - HS3 - S4 - HS4" where HS4 is the final hive stay (i.e., final state in the sequence). Next, the duration a forager spent in a given state was rounded to its nearest whole number (minimum duration of stay in a given state is $1 \mathrm{~min}$ ). Then, each search behavior profile (SPELL format) was converted into a search behavior sequence (STS format). The whole observation period of $120 \mathrm{~min}$ was divided into bins of $1 \mathrm{~min}$ and a forager occupied a given state for $1 \mathrm{~min}$ and moved into a new one or continued to be in the same state in the next $1 \mathrm{~min}$ depending on the search behavior profile. The sequences of search behavior states occupied by foragers were stored chronologically in a matrix (rows for every forager and the columns for a given state, see also Supplementary Material for details).

Finally, we calculated a distance matrix, that is, the distances between all pairs of search behavior sequences using the optimal matching distance metric. The metric used an insertion/deletion cost of 1 and substitution cost using transition rates $(\min =0$ for identical substitution and $\max =2$ for a transition not observed) between observed states in the search behavior sequence. Individuals with common search behavior sequences were grouped by hierarchical agglomerative clustering using Ward's D2 clustering criterion based on the distance matrix computed earlier. The optimal number of clusters was 
determined by selecting the maximum average silhouette width [Supplementary Figure 2A; (89)].

For collection experiments (CE 1-3), the search behavior profile for an individual making 2 search flights before being captured included the search behavior states: "FS - HFS - S1 HS1 - S2 - HS2" and HS2 was the final state in the sequence. A combination of sequence and cluster analysis was further done similar to behavioral experiments as mentioned before to identify common search behavior patterns among individual foragers following feeder removal (see also Supplementary Material for details). Foragers in CE 1-3 $(n=41)$ were grouped into three clusters (I-III; Figure 4A) based on the similarity in duration of stay in given states in their search behavior profile (Figure 4B; see also Supplementary Figure 2B for optimum number of clusters). Cluster I consisted of seven FS bees $(n=6,2018$ and $n=1,2019)$ which had their final stay in the hive (HFS) more than $20 \mathrm{~min}$ (Figures 4A,B). Cluster II had two S1 bees $(n=1,2018$ and $n$ $=1,2019$ ) which stayed in the hive (HS1) for more than $35 \mathrm{~min}$ before being captured. The biggest group, Cluster III consisted of S1, S2 and S3 bees $(n=15,2017, n=15,2018$ and $n=2$, 2019) which all had their final stay in the hive (HS1, HS2, and HS3 respectively) for $<20 \mathrm{~min}$.

Cluster III was further subdivided into five subgroups posthoc (IIIa-IIIe; Figures 4A,B). Subcluster IIIa comprises 13 FS bees which had their final stay in the hive (HFS) no longer than 14 min. Subcluster IIIc $(n=4)$ had all S2 bees but one individual (BeeID: C36) forming an outlier in subcluster IIIb with longer FS and search flights (S1 and S2 more than $18 \mathrm{~min}$ ). Subclusters IIId $(n=2)$ housed S1 bees which stayed in the hive (HS1) longer than $15 \mathrm{~min}$ (but $<35 \mathrm{~min}$ ) before being captured. Finally, subcluster IIIe $(n=12)$ housed the rest of the S1 bees which spent time in the hive (HS1) $<9 \mathrm{~min}$ before they were captured (see also Supplementary Material for details). This clustering further led to comparing neurotransmitters among individuals.

The sequence analysis was performed using the package "TraMineR" and agglomerative clustering was done by using the “agnes" function from package "cluster" in R version 4.0.2.

To help with the neurochemical data analysis, the FS and S bees without full behavioral data (seven bees) were manually classified into the identified clusters. For this purpose, the number of search flights and the total amount of time a bee experienced a loss of feeder before being caught were used in addition to incomplete flight duration and hive stay data. The details of the clustering criteria are given in the Supplementary Material.

\section{Quantification of Foragers Dynamics at the Feeder}

For BE 2, the total number of marked foragers at the feeder was counted every $2 \mathrm{~min}$ (Supplementary Figure 1). We asked if the rate of foraging was different during the foraging and revisiting phases. We fit non-linear growth curves to the number of bees at the feeder every 2 min to evaluate and compare the rate of foraging:

$$
\text { Gompertz curve : } \quad y=a e^{-b e^{-c t}}
$$

where $a=$ carrying capacity (maximum number of bees), $b=$ sets the displacement along the time-axis, $c=$ growth rate, $t=$ time in minutes and the inflection point (I) is given as Equation 2 (90).

$$
\text { Inflection Point : } \quad I=\left\{\frac{\ln b}{c}, e^{a-1}\right\}
$$

Gompertz curve fitting was done using the "nlsfit" function from package "easynls" in $\mathrm{R}$ version 4.0.2.

\section{Analysis of the Mass Spectrometry Results}

Neurochemical analysis was done using linear mixed effects models from the "lme4" package. Satterthwaite's $t$-tests from the "lmerTest" package were used to estimate significance values from the models. Analysis was done with the amount of neurochemical as the response variable, and the appropriate behavioral response/behavioral group as the fixed variable. The MS batch was used as the random effect. The formula (given in the R syntax) used for the model is as follows:

$$
\operatorname{lmer}(\text { Neurochemical } \sim \text { Groups }+(1 \mid \text { Batch }) \text {, data, REML }=\text { F })
$$

Post-hoc tests were done using the emmeans function from the "emmeans" package using the following code:

emmeans [model, list (pairwise $\sim$ Groups), adjust="tukey", lmer.df = "satterthwaite"]

Plots were drawn using the "ggplot2" package. For some plots, for visual purposes, the neurochemical values were scaled with respect to the MS batch and the experimental repeat.

PCA analysis was done using the "prcomps" function in the "stats" package of R. The package "ggbiplot" was used, with a minor adjustment for visual purposes, to plot the prcomp results.

\section{DATA AVAILABILITY STATEMENT}

The original contributions presented in the study are included in the article/Supplementary Material, further inquiries can be directed to the corresponding author/s.

\section{AUTHOR CONTRIBUTIONS}

AC, DR, and AB: conceptualization and writing. AC and DB: field experiments and observations. DB: brain dissections. AC: behavior analysis. DR: mass spectrometric measurements and analysis. AB: supervision. All authors contributed to the article and approved the submitted version.

\section{FUNDING}

AC was funded by a fellowship from University Grants Commission, India. DR was funded by the Council of Scientific and Industrial Research, India (Award No. CSIR-SPM-07/0860[0171]/2013-EMR-I). $\mathrm{AB}$ acknowledges support of NCBS-TIFR institutional funds No. 12P4167 and support of the Department of 
Atomic Energy, Government of India, under project no. 12-R\&D-TFR-5.04-0800 and 12-R\&D-TFR-5.040900.

\section{ACKNOWLEDGMENTS}

The authors would like to thank student interns A. Sengupta, A. Suryanarayanan, S. Chakraborty, D. Chowdhury, and

\section{REFERENCES}

1. Lindauer M. Ein beitrag zur frage der arbeitsteilung im bienenstaat. $Z \mathrm{Vgl}$ Physiol. (1952) 34:299-345. doi: 10.1007/BF00298048

2. Seeley TD. Division of labor between scouts and recruits in honeybee foraging. Behav Ecol Sociobiol. (1983) 12:253-9. doi: 10.1007/BF00290778

3. zu Oettingen-Spielberg T. Über das Wesen der Suchbiene. Z Vgl Physiol. (1949) 31:454-89. doi: 10.1007/BF00338037

4. Seeley TD. The Wisdom of the Hive: The Social Physiology of Honey Bee Colonies. Cambridge, MA: Harvard University Press (1995).

5. Liang ZS, Nguyen T, Mattila HR, Rodriguez-Zas SL, Seeley TD, Robinson GE. Molecular determinants of scouting behavior in honey bees. Science. (2012) 335:1225-8. doi: 10.1126/science.1213962

6. Liang ZS, Mattila HR, Rodriguez-Zas SL, Southey BR, Seeley TD, Robinson GE. Comparative brain transcriptomic analyses of scouting across distinct behavioural and ecological contexts in honeybees. Proc R Soc B. (2014) 281:20141868. doi: 10.1098/rspb.2014.1868

7. von Frisch K. Tanzsprache und Orientierung der Bienen. Berlin; Heidelberg; New York, NY: Springer (1965).

8. Riley JR, Greggers U, Smith AD, Reynolds DR, Menzel R. The flight paths of honeybees recruited by the waggle dance. Nature. (2005) 435:2057. doi: 10.1038 /nature 03526

9. Farina WM, Grüter C, Díaz PC. Social learning of floral odours inside the honeybee hive. Proc Biol Sci. (2005) 272:1923-8. doi: 10.1098/rspb.2005.3172

10. Bell WJ. Searching behavior patterns in insects. Annu Rev Entomol. (1990) 35:447-67. doi: 10.1146/annurev.en.35.010190.002311

11. Rachersberger M, Cordeiro GD, Schäffler I, Dötterl S. Honeybee pollinators use visual and floral scent cues to find apple (Malus domestica) flowers. J Agric Food Chem. (2019) 67:13221-7. doi: 10.1021/acs.jafc.9b06446

12. Reynolds AM, Smith AD, Reynolds DR, Carreck NL, Osborne JL. Honeybees perform optimal scale-free searching flights when attempting to locate a food source. J Exp Biol. (2007) 210:3763-70. doi: 10.1242/jeb.009563

13. Chatterjee A, George EA, Prabhudev MV, Basu P, Brockmann A. Honey bees flexibly use two navigational memories when updating dance distance information. J Exp Biol. (2019) 222:jeb195099. doi: 10.1242/jeb.195099

14. Srinivasan MV, Zhang SW, Bidwell NJ. Visually mediated odometry in honeybees. J Exp Biol. (1997) 200:2513-22. doi: 10.1242/jeb.200.19.2513

15. Townsend-Mehler JM, Dyer FC, Maida K. Deciding when to explore and when to persist: a comparison of honeybees and bumblebees in their response to downshifts in reward. Behav Ecol Sociobiol. (2011) 65:30512. doi: 10.1007/s00265-010-1047-4

16. Townsend-Mehler JM, Dyer FC. An integrated look at decision-making in bees as they abandon a depleted food source. Behav Ecol Sociobiol. (2012) 66:275-86. doi: 10.1007/s00265-011-1275-2

17. Toth AL, Kantarovich S, Meisel AF, Robinson GE. Nutritional status influences socially regulated foraging ontogeny in honey bees. J Exp Biol. (2005) 208:4641-9. doi: 10.1242/jeb.01956

18. Alaux C, Sinha S, Hasadsri L, Hunt GJ, Guzmán-Novoa E, DeGrandi-Hoffman G. et al. Honey bee aggression supports a link between gene regulation and behavioral evolution. Proc Natl Acad Sci USA. (2009) 106:154005. doi: 10.1073/pnas.0907043106

19. Shpigler HY, Saul MC, Murdoch EE, Cash-Ahmed AC, Seward CH, Sloofman L. et al. Behavioral, transcriptomic and epigenetic responses to social challenge in honey bees. Genes, Brain Behav. (2017) 16:579-91. doi: 10.1111/gbb. 12379
A. Chakrabarty for helping with the behavior experiments. The authors also thank the NCBS Mass Spectrometry facility.

\section{SUPPLEMENTARY MATERIAL}

The Supplementary Material for this article can be found online at: https://www.frontiersin.org/articles/10.3389/finsc. 2021.664978/full\#supplementary-material

20. Ramesh D, Brockmann A. Mass spectrometric quantification of arousal associated neurochemical changes in single honey bee brains and brain regions. ACS Chem Neurosci. (2019) 10:1950-9. doi: 10.1021/acschemneuro.8b00254

21. Kamhi JF, Barron AB, Narendra A. Vertical lobes of the mushroom bodies are essential for view-based navigation in Australian Myrmecia ants. Curr Biol. (2020) 30:3432-7. doi: 10.1016/j.cub.2020.06.030

22. Buehlmann C, Wozniak B, Goulard R, Webb B, Graham P, Niven JE. Mushroom bodies are required for learned visual navigation, but not for innate visual behavior, in ants. Curr Biol. (2020) 30:343843. doi: 10.1016/j.cub.2020.07.013

23. Stone T, Webb B, Adden A, Weddig NB, Honkanen A, Templin R. et al. An anatomically constrained model for path integration in the bee brain. Curr Biol. (2017) 27:3069-85. doi: 10.1016/j.cub.2017.08.052

24. Seelig JD, Jayaraman V. Neural dynamics for landmark orientation and angular path integration. Nature. (2015) 521:18691. doi: 10.1038/nature14446

25. Brockmann A, Robinson GE. Central projections of sensory systems involved in honey bee dance language communication. Brain Behav Evol. (2007) 70:125-36. doi: 10.1159/000102974

26. Yilmaz A, Grübel K, Spaethe J, Rössler W. Distributed plasticity in ant visual pathways following colour learning. Proc Biol Sci. (2019) 13:20182813. doi: $10.1098 /$ rspb.2018.2813

27. Zeller M, Held M, Bender J, Berz A, Heinloth T. Hellfritz et al. Transmedulla neurons in the sky compass network of the honeybee (Apis mellifera) are a possible site of circadian input. PLOS ONE. (2015) 10:e0143244. doi: 10.1371/journal.pone.0143244

28. Al Toufailia H, Grüter C, Ratnieks FL. Persistence to unrewarding feeding locations by honeybee foragers (Apis mellifera): the effects of experience, resource profitability and season. Ethology. (2013) 119:1096-116. doi: $10.1111 /$ eth. 12170

29. Biesmeijer JC, de Vries. H. Exploration and exploitation of food sources by social insect colonies: a revision of the scout-recruit concept. Behav Ecol Sociobiol. (2001) 49:89-99. doi: 10.1007/s002 650000289

30. George EA, Bröger A, Thamm M, Brockmann A, Scheiner R. Inter-individual variation in honey bee dance intensity correlates with expression of the foraging gene. Genes, Brain Behav. (2020) 19:e12592. doi: 10.1111/gbb.12592

31. Carr-Markell MK, Robinson GE. Comparing reversal-learning abilities, sucrose responsiveness, and foraging experience between scout and nonscout honey bee (Apis mellifera) foragers. J Insect Behav. (2014) 27:73652. doi: 10.1007/s10905-014-9465-1

32. Cook CN, Mosqueiro T, Brent CS, Ozturk C, Gadau J, Pinter-Wollman N. et al. Individual differences in learning and biogenic amine levels influence the behavioural division between foraging honey bee scouts and recruits. J Anim Ecol. (2019) 88:236-46. doi: 10.1111/1365-2656.12911

33. Filla I, Menzel R. Mushroom body extrinsic neurons in the honeybee (Apis mellifera) brain integrate context and cue values upon attentional stimulus selection. J Neurophysiol. (2015) 114:2005-14. doi: 10.1152/jn. 00776.2014

34. Locatelli F, Bundrock G, Müller U. Focal and temporal release of glutamate in the mushroom bodies improves olfactory memory in Apis mellifera. $J$ Neurosci. (2005) 25:11614-8. doi: 10.1523/JNEUROSCI.3180-05.2005

35. Alleman A, Stoldt M, Feldmeyer B, Foitzik S. Tandem-running and scouting behaviour are characterized by up-regulation of learning and 
memory formation genes within the ant brain. Mol Ecol. (2019) 28:234259. doi: $10.1111 / \mathrm{mec} .15079$

36. Degen J, Hovestadt T, Storms M, Menzel R. Exploratory behavior of reorienting foragers differs from other flight patterns of honeybees. PLoS ONE. (2018) 13:e0202171. doi: 10.1371/journal.pone.0202171

37. Kiya. T, Kubo T. Analysis of GABAergic and non-GABAergic neuron activity in the optic lobes of the forager and re-orienting worker honeybee (Apis mellifera L.). PLoS ONE. (2010) 5:e8833. doi: 10.1371/journal.pone.0008833

38. Lehrer M. Bees which turn back and look. Naturwissenschaften. (1991) 78:2746. doi: 10.1007/BF01134357

39. Keleş MF, Hardcastle BJ, Städele C, Xiao Q, Frye MA. Inhibitory interactions and columnar inputs to an object motion detector in Drosophila. Cell Rep. (2020) 30:2115-24. doi: 10.1016/j.celrep.2020.01.061

40. Keleş MF, Frye MA. Object-detecting neurons in Drosophila. Curr Biol. (2017) 27:680-7. doi: 10.1016/j.cub.2017.01.012

41. Bicker G, Schafer S, Ottersen OP, Storm-Mathisen J. Glutamatelike immunoreactivity in identified neuronal populations of insect nervous systems. J Neurosci. (1988) 8:210822. doi: 10.1523/JNEUROSCI.08-06-02108.1988

42. Rossi M, Hausmann AE, Thurman TJ, Montgomery SH, Papa R, Jiggins $\mathrm{CD}$. et al. Visual mate preference evolution during butterfly speciation is linked to neural processing genes. Nat Commun. (2020) 11:4763. doi: 10.1038/s41467-020-18609-z

43. Sinakevitch I, Strausfeld NJ. Chemical neuroanatomy of the fly's movement detection pathway. J Comp Neurol. (2004) 468:6-23. doi: 10.1002/cne.10929

44. Cheng KY, Frye MA. Neuromodulation of insect motion vision. J Comp Physiol. A. (2020) 206:125-37. doi: 10.1007/s00359-019-01383-9

45. Hamanaka Y, Kinoshita M, Homberg U, Arikawa K. Immunocytochemical localization of amines and GABA in the optic lobe of the butterfly, Papilio xuthus. PLoS ONE. (2012) 7:e41109. doi: 10.1371/journal.pone.0041109

46. Thamm M, Scholl C, Reim T, Grübel K, Möller K, Rössler W. et al. Neuronal distribution of tyramine and the tyramine receptor AmTAR1 in the honeybee brain. J Comp Neurol. (2017) 525:2615-31. doi: 10.1002/cne.24228

47. Ziegler AB, Brüsselbach F, Hovemann BT. Activity and coexpression of Drosophila black with ebony in fly optic lobes reveals putative cooperative tasks in vision that evade electroretinographic detection. J Comp Neurol. (2013) 521:1207-24. doi: 10.1002/cne.23247

48. Torrealba F, Riveros ME, Contreras M, Valdes JL. Histamine and motivation. Front Syst Neurosci. (2012) 6:51. doi: 10.3389/fnsys.2012.00051

49. Linn M, Glaser SM, Peng T, Grüter C. Octopamine and dopamine mediate waggle dance following and information use in honeybees. Proc $R$ Soc $B$. (2020) 287:20201950. doi: 10.1098/rspb.2020.1950

50. Barron $A B$, Robinson GE. Selective modulation of task performance by octopamine in honey bee (Apis mellifera) division of labour. J Comp Physiol A. (2005) 191:659-68. doi: 10.1007/s00359-005-0619-7

51. Wagener-Hulme C, Kuehn JC, Schulz DJ, Robinson GE. Biogenic amines and division of labor in honey bee colonies. J Comp Physiol A. (1999) 184:471-9. doi: 10.1007/s003590050347

52. Barron AB, Schulz DJ, Robinson GE. A role for octopamine in honey bee division of labor. Brain Behav Evol. (2002) 60:350-9. doi: 10.1159/000067788

53. Hunt GJ, Amdam GV, Schlipalius D, Emore C, Sardesai N, Williams CE. et al. Behavioral genomics of honeybee foraging and nest defense. Naturwissenschaften. (2007) 94:247-67. doi: 10.1007/s00114-0060183-1

54. BoŽič J, Woodring J. Variations of brain biogenic amines in mature honeybees and induction of recruitment behavior. Comp Biochem Physiol A Mol Integr Physiol. (1998) 120:737-44. doi: 10.1016/S1095-6433(98)10094-6

55. Harris JW, Woodring J. Effects of stress, age, season, and source colony on levels of octopamine, dopamine and serotonin in the honey bee (Apis mellifera L.) brain. J Insect Physiol. (1992) 38:29-35. doi: 10.1016/0022-1910(92)90019-A

56. Hewlett SE, Delahunt Smoleniec JD, Wareham DM, Pyne TM, Barron AB. Biogenic amine modulation of honey bee sociability and nestmate affiliation. PLoS ONE. (2018) 13:1-18. doi: 10.1371/journal.pone.0205686

57. Mayack C, Naug D. Starving honeybees lose self-control. Biol Lett. (2015) 11:20140820. doi: 10.1098/rsbl.2014.0820

58. Palmer CR, Kristan Jr WB. Contextual modulation of behavioral choice. Curr Opin Neurobiol. (2011) 21:520-6. doi: 10.1016/j.conb.2011.05.003
59. Sherer LM, Garrett EC, Morgan HR, Brewer ED, Sirrs LA, Shearin HK, et al. Octopamine neuron dependent aggression requires dVGLUT from dual-transmitting neurons. PLoS Genet. (2020) 16:e1008609. doi: 10.1371/journal.pgen.1008609

60. Gauthier M, Grünewald B. Neurotransmitter systems in the honey bee brain: functions in learning and memory. In: Galizia C, Eisenhardt D, Giurfa M, editors. Honeybee Neurobiology and Behavior. Dordrecht: Springer (2012). p. 155-69.

61. Leboulle G. Glutamate neurotransmission in the honey bee central nervous system. In: Galizia C, Eisenhardt D, Giurfa M, editors. Honeybee Neurobiology and Behavior. Dordrecht: Springer (2012). p. 171-84.

62. Shyu W-H, Chiu T-H, Chiang M-H, Cheng Y-C, Tsai Y-L, Fu T-F, et al. Neural circuits for long-term water-reward memory processing in thirsty Drosophila. Nat Commun. (2017) 8:1-13. doi: 10.1038/ncomms 15230

63. Xia S, Miyashita T, Fu T-F, Lin W-Y, Wu C-L, Pyzocha L, et al. NMDA receptors mediate olfactory learning and memory in Drosophila. Curr Biol. (2005) 15:603-15. doi: 10.1016/j.cub.2005.02.059

64. Zwaka H, Bartels R, Grünewald B, Menzel R. Neural organization of A3 mushroom body extrinsic neurons in the honeybee brain. Front Neuroanat. (2018) 12:57. doi: 10.3389/fnana.2018.00057

65. Cammaerts-Tricot MC, Cammaerts R. Effect of monosodium glutamate on behavior and cognition: a study using ants as biological models. Ann Public Heal Res. (2016) 3:3.

66. Huber F. Sitz und Bedeutung nervöser Zentren für Instinkthandlungen beim Männchen von Gryllus campestris L. Z Tierpsychol. (1955) 12:1248. doi: 10.1111/j.1439-0310.1955.tb01513.x

67. Hulse BK, Haberkern H, Franconville R, Turner-Evans DB, Takemura S, Wolff T. et al. A connectome of the Drosophila central complex reveals network motifs suitable for flexible navigation and context-dependent action selection. bioRxiv. (2020). doi: 10.1101/2020.12.08.413955

68. Tsao C-H, Chen C-C, Lin C-H, Yang H-Y, Lin S. Drosophila mushroom bodies integrate hunger and satiety signals to control innate food-seeking behavior. Elife. (2018) 7:e35264. doi: 10.7554/eLife.35264

69. Varga AG, Kathman ND, Martin JP, Guo P, Ritzmann RE. Spatial navigation and the central complex: sensory acquisition, orientation, motor control. Front Behav Neurosci. (2017) 11:4. doi: 10.3389/fnbeh.2017. 00004

70. Sommerlandt FMJ, Brockmann A, Rössler W, Spaethe J. Immediate early genes in social insects: a tool to identify brain regions involved in complex behaviors and molecular processes underlying neuroplasticity. Cell Mol Life Sci. (2019) 76:637-51. doi: 10.1007/s00018-018-2948-z

71. Giurfa M. Learning and cognition in insects. Wiley Interdiscip Rev Cogn Sci. (2015) 6:383-95. doi: 10.1002/wcs.1348

72. Reinhard J, Srinivasan MV, Zhang S. Scent-triggered navigation in honeybees. Nature. (2004) 427:411. doi: 10.1038/427411a

73. Shah A, Jain R, Brockmann A. Egr-1: a candidate transcription factor involved in molecular processes underlying time-memory. Front Psychol. (2018) 9:865. doi: 10.3389/fpsyg.2018.00865

74. Brockmann A, Annangudi SP, Richmond TA, Ament SA, Xie F, Southey BR. et al. Quantitative peptidomics reveal brain peptide signatures of behavior. Proc Natl Acad Sci USA. (2009) 106:2383-8. doi: 10.1073/pnas.08130 21106

75. Singh AS, Shah A, Brockmann A. Honey bee foraging induces upregulation of early growth response protein 1 , hormone receptor 38 and candidate downstream genes of the ecdysteroid signalling pathway. Insect Mol Biol. (2018) 27:90-8. doi: 10.1111/imb.12350

76. Barron AB, Maleszka R, Vander Meer RK, Robinson GE. Octopamine modulates honey bee dance behavior. Proc Natl Acad Sci USA. (2007) 104:1703-7. doi: 10.1073/pnas.0610506104

77. George EA, Brockmann A. Social modulation of individual differences in dance communication in honey bees. Behav Ecol Sociobiol. (2019) 73:41. doi: 10.1007/s00265-019-2649-0

78. Jeanson $\mathrm{R}$, Weidenmüller $\mathrm{A}$. Interindividual variability in social insectsproximate causes and ultimate consequences. Biol Rev. (2014) 89:67187. doi: $10.1111 /$ brv. 12074

79. Kiya. T, Kubo T. Dance type and flight parameters are associated with different mushroom body neural activities in worker honey bee brains. PLOS ONE. (2011) 6:e19301. doi: 10.1371/journal.pone.0019301 
80. Degirmenci L, Geiger D, Rogé Ferreira FL, Keller A, Krischke B, Beye M. et al. CRISPR/Cas 9-mediated mutations as a new tool for studying taste in honeybees. Chem Senses. (2020) 45:655-66. doi: 10.1093/chemse/ bjaa063

81. Kohno H, Suenami S, Takeuchi H, Sasaki T, Kubo T. Production of knockout mutants by crispr/cas9 in the european honeybee, Apis mellifera L. Zoolog Sci. (2016) 33:505-12. doi: 10.2108/zs160043

82. Roth A, Vleurinck C, Netschitailo O, Bauer V, Otte M, Kaftanoglu O. et al. A genetic switch for worker nutrition-mediated traits in honeybees. PLoS Biol. (2019) 17:e3000171. doi: 10.1371/journal.pbio. 3000171

83. Brockmann A, Basu P, Shakeel M, Murata S, Murashima N, Boyapati RK. et al. Sugar intake elicits intelligent searching behavior in flies and honey bees. Front Behav Neurosci. (2018) 12:280. doi: 10.3389/fnbeh.2018. 00280

84. Kamhi JF, Arganda S, Moreau CS, Traniello JFA. Origins of aminergic regulation of behavior in complex insect social systems. Front Syst Neurosci. (2017) 11:74. doi: 10.3389/fnsys.2017.00074

85. Murata S, Brockmann A, Tanimura T. Pharyngeal stimulation with sugar triggers local searching behavior in Drosophila. J Exp Biol. (2017) 220:32317. doi: $10.1242 /$ jeb. 161646

86. Reaume CJ, Sokolowski MB. Conservation of gene function in behaviour. Philos Trans R Soc B. (2011) 366:2100-10. doi: 10.1098/rstb.2011.0028
87. Natarajan N, Ramakrishnan P, Lakshmanan V, Palakodeti D, Rangiah K. A quantitative metabolomics peek into planarian regeneration. Analyst. (2015) 10:3445-64. doi: 10.1039/C4AN02037E

88. Lowe MR, Holbrook CM, Hondorp DW. Detecting commonality in multidimensional fish movement histories using sequence analysis. Anim Biotelemetry. (2020) 8:1-14. doi: 10.1186/s40317-020-00195-y

89. Levshina N. How To Do Linguistics With R: Data Exploration and Statistical Analysis. Amsterdam; Philadelphia, PA: John Benjamins Publishing Company (2015). doi: 10.1075/z.195

90. Jukić D, Kralik G, Scitovski R. Least-squares fitting Gompertz curve. J Comput Appl Math. (2004) 169:359-75. doi: 10.1016/j.cam.2003.12.030

Conflict of Interest: The authors declare that the research was conducted in the absence of any commercial or financial relationships that could be construed as a potential conflict of interest.

Copyright (C) 2021 Chatterjee, Bais, Brockmann and Ramesh. This is an open-access article distributed under the terms of the Creative Commons Attribution License (CC $B Y)$. The use, distribution or reproduction in other forums is permitted, provided the original author(s) and the copyright owner(s) are credited and that the original publication in this journal is cited, in accordance with accepted academic practice. No use, distribution or reproduction is permitted which does not comply with these terms. 